\title{
Cell Surface Morphology Identifies Microglia as a Distinct Class of Mononuclear Phagocyte
}

\author{
Dana Giulian, ${ }^{1}$ Jun Li, ${ }^{1}$ Sandra Bartel, ${ }^{1}$ Jennifer Broker, ${ }^{1}$ Xia Li, ${ }^{1}$ and Joel B. Kirkpatrick ${ }^{2}$ \\ 'Department of Neurology, 'Baylor Center for AIDS Research, 'Department of Pathology, and 1,2Alzheimer's \\ Disease Research Center, Baylor College of Medicine, Houston, Texas 77030
}

To investigate differences among brain-derived microglia and other classes of immune cells, we compared the morphologies and growth properties of mononuclear phagocytes isolated from tissues of the newborn rat. Scanning EM shows that microglia from postnatal rat brain are covered with spines (typically $>20$ per cell body) in a distinctive manner which contrasts the smooth surfaces of bone marrow cells and the ruffled surfaces of tissue macrophages from spleen, liver, and peritoneum. The spine-bearing surface of microglia is a specific cell marker, for it does not change with age or after exposure to cytokines or other immunostimulants. Approximately $99 \%$ of mononuclear phagocytes cultured from normal adult rat brain are spinous microglia. Five days after injury to rat brain, cells at sites of Wallerian degeneration are essentially all spinous ones while nearly $30 \%$ of cells found within areas of infarction or penetrating trauma are invading macrophages. In a similar way, nearly all cells isolated from normal, postmortem adult human brain are spine-bearing microglia ( $>99 \%$ homogeneity). Brains from patients with amyotrophic lateral sclerosis contain only spinous microglia whereas cells from HIV-1 infected brains include significant numbers of invading ruffled macrophages.

Cultured microglia, unlike cultured bone marrow precursors, monocytes, or tissue macrophages, spontaneously develop long, thin processes that extend hundreds of microns in length. Microglia retract these processes after exposure to fetal bovine serum, laminin, or such immunostimulants as recombinant murine interferon $\gamma$ ( $\mathrm{rmIFN} \gamma$ ) and lipopolysaccharide. Of all types of mononuclear phagocytes tested, only microglia differentiate into quiescent ramified cells when in contact with astrocytes. Thus, microglia represent a unique class of cell maintained, in part, by astroglia as dormant, ramified mononuclear phagocytes in mature CNS. Application of cell surface criteria described here will allow study of distinct populations of mononuclear phagocytes associated with neurologic disorders.

[Key words: microglia, macrophages, monocytes, cyto-

Received June 9, 1995; revised July 24, 1995; accepted July 31, 1995.

The work was supported by NIH Grants NS25637, NS23113, and MH48652, The Vivian Smith Foundation, Alzheimer's Association, and Baylor's Alzheimer's Disease Research Center.

Correspondence should be addressed to Dana Giulian, M.D., Ph.D., Department of Neurology, Baylor College of Medicine, One Baylor Plaza, Houston, TX 77030

Copyright $(\mathcal{O} 1995$ Society for Neuroscience 0270-6474/95/157712-15\$05.00/0 kines, brain injury, development, neurodegeneration, HIV1, rat, human]

Microglia, a class of brain mononuclear phagocyte, are thought to be the principal immune cells resident to the CNS (Giulian, 1992; Flaris et al., 1993). The functional capacities of microglia have received increasing attention as these cells have been found to be the major source of brain cytokines (Giulian and Lachman, 1985; Hetier et al., 1990; Higgins and Olschowka, 1991) and have been implicated in the destruction of neurons during stroke (Giulian and Robertson, 1990; Giulian et al., 1993), trauma (Banati et al., 1993; Thanos et al., 1993), Alzheimer's disease (Bolsi, 1927; McGeer et al., 1987; Giulian et al., 1995), and HIV-1 infection (Giulian et al., 1990). Primitive stem cells, which give rise to microglia, are first seen in the periventricular regions during early embryonic development and eventually take up residence throughout the fetal brain (Rio-Hortega, 1932; Ling, 1981). In the late fetal and early neonatal periods, maturing microglia differentiate from the ameboid into ramified forms, characteristic of the quiescent cells found in the adult nervous system (Rio-Hortega, 1932).

Although many investigators accept the hypothesis that stem cells common to all classes of mononuclear phagocytes give rise to microglia in early stages of development (Rio-Hortega, 1932; Ling and Wong, 1993), there is less agreement as to the relalionships among microglia and other classes of mononuclear phagocytes after birth (Imamoto and Leblond, 1977). During CNS pathology, microglia have been described either as a distinct cell population (Hickey and Kimura, 1988) or, alternatively, as a wave of invading blood monocytes (Perry et al., 1985; Jordan and Thomas, 1988). Part of this controversy arises from the fact that cell markers expressed in developing microglia are often difficult to detect in mature, ramified cells (Perry et al., 1993). For example, nonspecific esterase, which is expressed by peripheral mononuclear phagocytes throughout development, is normally only seen in microglia during fetal and early postnatal development (Giulian and Baker, 1986). Because nonspecific esterase $(+)$ cells exist within the newborn rat brain, Ling et al (1982) concluded that blood cells invade the postnatal brain, while other investigators finding no macrophagic makers in mature brain came to an opposing conclusion (Wood et al., 1976; Oehmichen, 1983). In general, efforts to establish a pancl of microglia-specific markers have proved elusive, with expression dependent upon age, species and prior exposure to immunostimulants (Giulian, 1992; Flaris et al., 1993; Ulvestad et al., 1994). Despite the uncertainties associated with histochemical markers, observations based upon other techniques suggest microglia to be a distinct class of cell. Unlike differentiated blood monocytes, 
microglia may proliferate in postnatal and adult brain (Graeber et al., 1988; Giulian et al., 1989), suggesting features of stem cells found in bone marrow. Patch clamp study of membrane conductances (Kettenmann et al., 1990) demonstrates inward directed rectifying potassium currents for microglia which are not found in monocytes or macrophages. Moreover, Hickey and $\mathrm{Ki}$ mura (1988) note that parenchymal microglia of adult chimeric rats do not arise from marrow-derived stem cells or blood borne monocytes.

In this report, we compare brain-derived mononuclear phagocytes recovered from newborn rat with other classes of mononuclear phagocytes isolated from newborn blood, spleen, liver, marrow, and peritoneum. We find that cultured microglia display distinctive features including surface morphology, patterns of differentiation, and responsiveness to cytokines. Moreover, scanning EM distinguishes microglia from invading blood-borne macrophages at sites of adult brain injury. Although astrocyte contacts with microglia accelerate differentiation of ameboid cells into quiescent ramified ones, astroglia do not shape the behaviors of other classes of mononuclear phagocytes. Further, study of human brain cells indicate scanning EM to be a useful technique to characterize inflammation associated with neurological disease.

\section{Materials and Methods}

Isolation and identification of cells. Mononuclear phagocytes were identified by their ability to engulf fluorescent polystyrene microspheres $(0.7$ $\mu \mathrm{m}$, Covaspheres Particles, FX Green, Duke Scientific, Palo Alto, CA), by the presence of scavenger receptors (Giulian and Baker, 1985; Giulian et al., 1989) visualized with the fluorescent probe $1,1^{\prime}$-dioctadecyl1,3,3,3',3-tetramethyl-indo-carbocyanine bound to acetylated low density lipoprotein (DiI-ac-LDL; obtained from Biomedical Technologics Inc., Stoughton, MA), by the presence of nonspecific esterase activity (Koski et al., 1981), and by immunostaining with the OX-42 antibody (Serolec, Kidlington, England) at $30 \mu \mathrm{g} / \mathrm{ml}$. Astroglia were identified by immuno-labeling for glial fibrillary acidic protein (GFAP) using rabbit anti-bovine GFAP (Dako, Glostrup, Denmark) at $40 \mu \mathrm{g} / \mathrm{ml}$ as described previously (Giulian et al., 1986).

Mononuclear phagocytes were isolated directly from various organs of rat following enzymatic/mechanical dissociation of tissues, separation by a ficol/sodium diatrizoate gradient (Histopaque 1077; Sigma, St. Louis, MO), and selective adhesion to glass or plastic (Giulian and Baker, 1986). All cells were grown on glass coverslips in chemically defined N2 medium (Bottenstein and Sato, 1979) free of serum. Brain, liver, and spleen were mechanically dissociated in the presence of $0.2 \%$ trypsin (T-2904, Sigma) plus $0.2 \mathrm{mg} / \mathrm{ml}$ of DNase (D-5025, Sigma) for $15 \mathrm{~min}$ at $37^{\circ} \mathrm{C}$. Blood monocytes (Boyum, 1968), resident macrophages lavaged from the peritoneum (Daems, 1980), and femur marrow aspirates (Stewarl, 1981) were mechanically dispersed without protease by trituration for $10 \mathrm{~min}$. In some experiments, highly enriched populations of ameboid microglia and astroglia were isolated from confluent dissociated brain cell cultures by rotatory shaking for $18 \mathrm{hr}$ with the suspension of "freed" cells collected by two rounds of selective adhesion to plastic as described earlier (Giulian and Baker, 1986). The remaining feeder layers of astroglia were treated with carbonyl iron (1.5 $\mu \mathrm{g}$ per $\mathrm{cm}^{2}$ of culture dish surface) once per day for 2 consecutive days in order to eliminate phagncytic microglia by a magnet (Advanced Magnets, Inc.; Cambridge, MA). These enriched astroglia [ $>99 \%$ homogeneous population of GFAP $(+)$ cells] were mechanically dissociated in the presence of $0.2 \%$ trypsin and were then seeded in $100 \mathrm{~mm}$ culture dishes at a density of $0.5 \times 10^{6}$ cells per $\mathrm{ml}$ of chemically defined N2 medium (Bottenstein and Sato, 1979). Typically, these enriched astroglia preparations contained $<0.1 \%$ of DiI-ac-LDL(+) microglia. Cuculture experiments involved $2.5>10^{5}$ microglia in $1 \mathrm{ml}$ of $\mathrm{N} 2$ culture medium to Millicell-CM chamb $s(0.4 \mu \mathrm{m}$ filter pore size; Millipore) atop coverslips holding $5 \times 10^{\circ}$ purified astroglia.

Viable adult human microglia were recovered at the time of autopsy from neocortical gray matter within a postmortem interval of $<6 \mathrm{hr}$. Tissues from brains were dissociated by trituration in $0.15 \%$ trypsin, placed in N2 media with $10 \%$ fetal bovine serum, centrifuged through
A

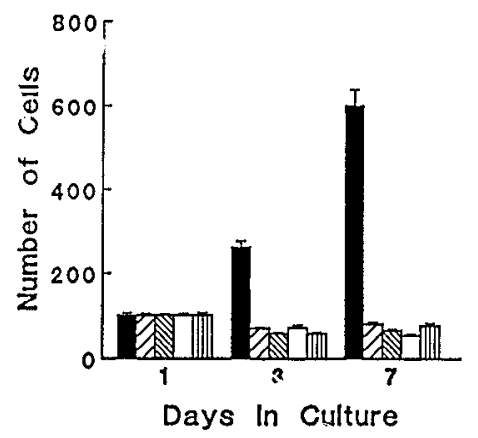

Microglia

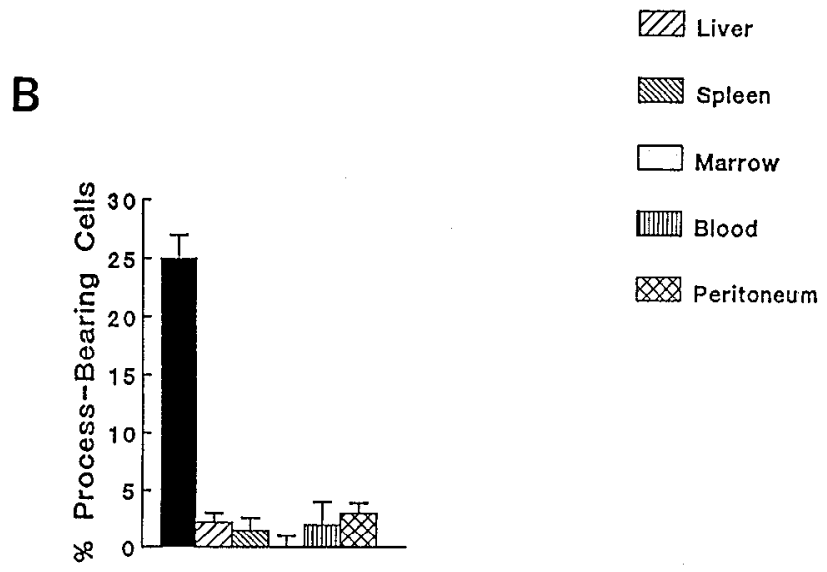

Figure 1. A, Proliferation of mononuclear phagocytes isolated from different tissues of newborn rat. When placed in chemically defined culture media free of serum, only cells isolated from brain showed spontaneous proliferation. $B$. Mean frequency of process bearing cells for classes of mononuclear phagocytes was scored with a process defined as $>3$-fold cell body diameter. As shown, about $25 \%$ microglia underwent ramification by $3 \mathrm{~d}$ in vitro.

$35 \%$ sucrose and separated by a ficol/sodium diatrizoate gradient (Histopaque 1077; Sigma, St. Louis, MO). Cells were placed in N2 media containing gentamycin $(48 \mu \mathrm{g} / \mathrm{ml})$ and recovered by selective adhesion to plastic for $12 \mathrm{hr}$ (Giulian and Baker, 1986). We typically recover 1 $3 \times 10^{5}$ cells per gram wet weight of tissue. Amyotrophic lateral sclerosis brains were from patients with neurogenic atrophy of skeletal muscles, loss of anterior horn cells, and spared intellectual function. Normal control brains were from adult patients with no brain pathology. HIV$1(+)$ brain tissues were acquired from infected adults showing microglial nodules and giant cells but lacking evidence of other pathology including parasitic infection, neoplasm, infarction, or abscess.

Mononuclear phagocytes were studied after exposure to lipopolysaccharide (LPS, \#3120-25-0, Difco, Detroit, MI), recombinant murine tumor necrosis factor $\alpha$ (rmTNF $\alpha$, \#B3368, Genzyme, Cambridge, MA), recombinant murine interleukin- $1 \alpha$ (rmIL- $1 \alpha$, \#B1457, Genzyme), recombinant murine interferon $\gamma$ (rmIFN $\gamma$, \#B4990, Genzyme), recombinant murine granulocyte macrophage colony stimulating factor (rmGM-CSF, \#B3630, Genzyme), laminin (\#08-125, UBI, Lake Placid, NY), fibronectin (\#F1141, Sigma), collagen IV (\#C0543, Sigma), and fetal bovine serum (\#F2442, Sigma).

Scanning electron microscopy. Cells adhering to glass coverslips were fixed in $2 \%$ glutaraldehyde in $50 \mathrm{~mm}$ cacodylate buffer $\mathrm{pH} 7.4$ containing $0.1 \mathrm{M}$ sucrose for $30 \mathrm{~min}$ at $37^{\circ} \mathrm{C}$. After several rinses with phosphate-buffered saline, the cells were postfixed in $2 \% \mathrm{OsO}_{4}$ in 0.1 $\mathrm{M}$ phosphate buffer, $\mathrm{pH} 7.4$ for $1 \mathrm{hr}$ at $4^{\circ} \mathrm{C}$. Following dehydration with a graded series of ethanol, the cells were washed three times with $100 \%$ acetone, dried under $\mathrm{CO}_{2}$ in a critical point drying apparatus (Denton Vacuum, Cherry Hill, NJ) and coated with gold (Denton Sputter Etch Unit). Samples were mounted on copper specimen boats with conduc- 

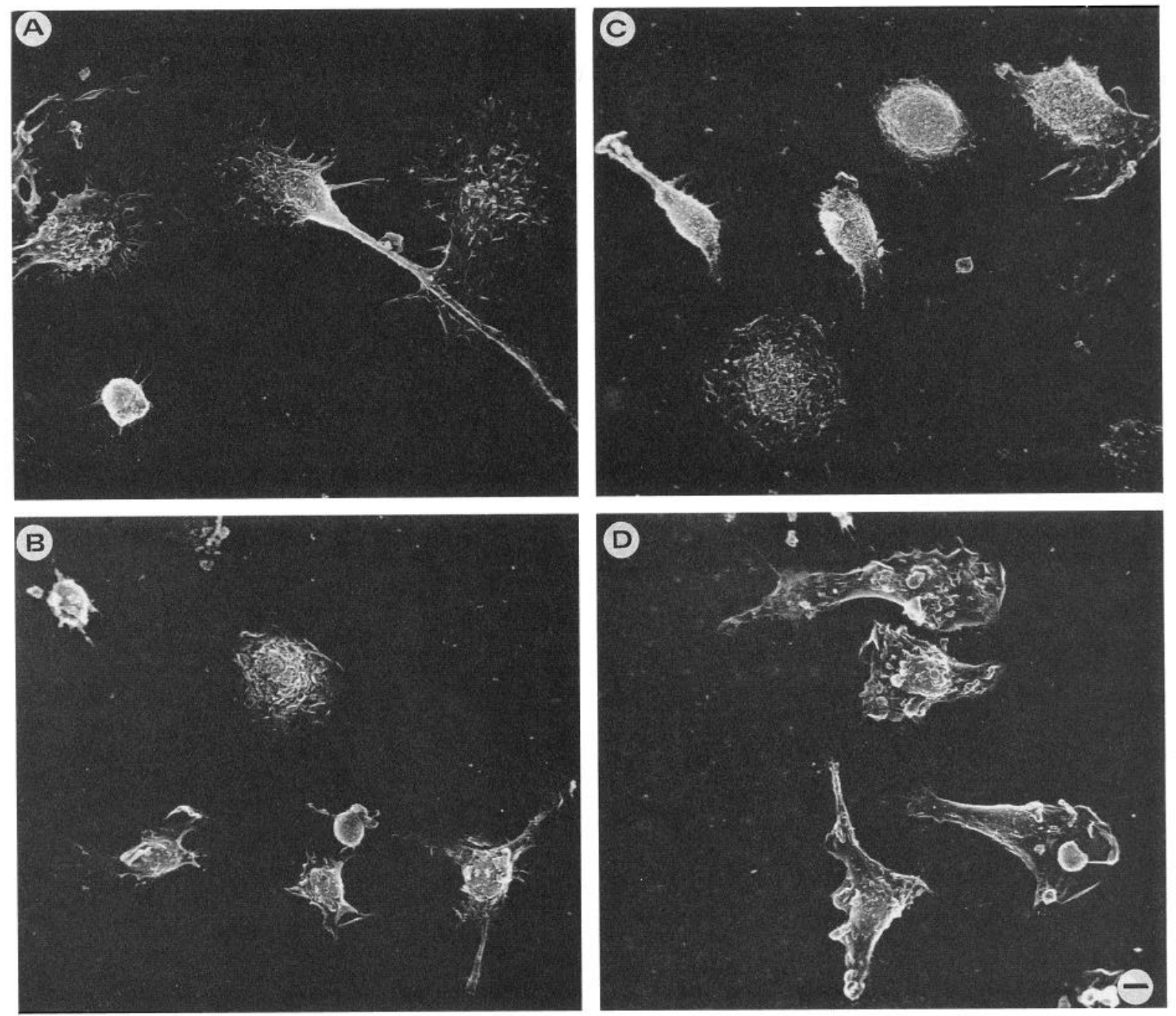

Figure 2. Scanning electron photomicrographs showing the surface features of mononuclear phagocytes of the newborn rat isolated from different tissues and maintained in culture for $3 \mathrm{~d}$. A, Microglia recovered from the newborn brain show both long processes and spines which radiate out from cell body. $B$, Peritoneal macrophages remain ameboid in shape with a ruffled surface membrane, few spines, and short stubby projections. $C$, Round, smooth profiles of bone marrow mononuclear phagocytes. $D$, Short, stubby processes and ruffled surfaces are the main features of spleenderived macrophages. Scale bar, $5 \mu \mathrm{m}$.

tive colloidal silver and viewed using a JEOL JEM-100 CX between 500 and 10,000 magnification.

Brain injury models. Optic nerve transection was carried out in adult albino rats anesthetized by intraperitoneal injection using a combination anesthetic $(0.14 \mathrm{mg}$ ketamine, $0.29 \mathrm{mg}$ xylazine, and $0.014 \mathrm{mg}$ acepromazine per $100 \mathrm{gm}$ body weight). The optic nerve was exposed by an incision placed through the lateral palebral fissure and the nerve was transected while sparing the ophthalmic artery. Reactive microglia associated with degenerating axons were recovered from the optic tecta

\section{Table 1. GM-CSF effect on microglial ramification}

\begin{tabular}{llc} 
& \multicolumn{2}{l}{ Mean process lengths $(\mu \mathrm{m} \pm \mathrm{SEM})$} \\
\cline { 2 - 3 } & Control & rmGM-CSF \\
\hline Macrophages & $38.2 \pm 2.7$ & $35.5 \pm 2.8$ \\
Microglia & $99.5 \pm 8.8$ & $157.0 \pm 10.9$ \\
\hline
\end{tabular}

Isolated peritoneal macrophages and microglia were placed in culture for $3 \mathrm{~d}$ in the presence or absence of 50 units $/ \mathrm{ml}$ of rmGM-CSF. Scanning EM was used to measure process lengths from 100 randomly selected cells defined as process-bearing (process lengths $>3 \times$ diameter of the cell body).
$5 \mathrm{~d}$ post axotomy using standard methods as described above. Penetrating injury to the neocortex was produced with a microknife in adult albino rats deeply anesthetized and placed in a stereotaxic device (David Kopf Inc., Tujunga, CA). After the scalp was reflected, burr holes were placed $1 \mathrm{~mm}$ lateral to either side of the midline and rostral to caudal incisions were inflicted by a microknife at a depth of $3 \mathrm{~mm}$. Reactive microglia and invading macrophages were recovered from dissociated neocortex in the region of injury after $5 \mathrm{~d}$. Transient ischemia was produced by occlusion of the middle cerebral artery in adult rats (Hsu et al., 1990). Using microsurgical techniques, a burr hole was made 1 $\mathrm{mm}$ rostral to the anterior junction of the zygomatic and temporal bones. Both common carotid arteries were occluded with clips, after which the right middle cerebral artery was temporarily blocked by retraction with a curved $100 \mu \mathrm{m}$ diameter needle. After $45 \mathrm{~min}$, the needle and clips were removed and the wounds sutured. Reactive microglia and invading macrophages were recovered from cortical infarcts $5 \mathrm{~d}$ after injury (Giulian et al., 1993).

\section{Results}

Distinctive microglial patterns of cell survival and differentiation

To assess differences among populations of mononuclear phagocytes, we compared the behaviors of cells isolated from brain 
A

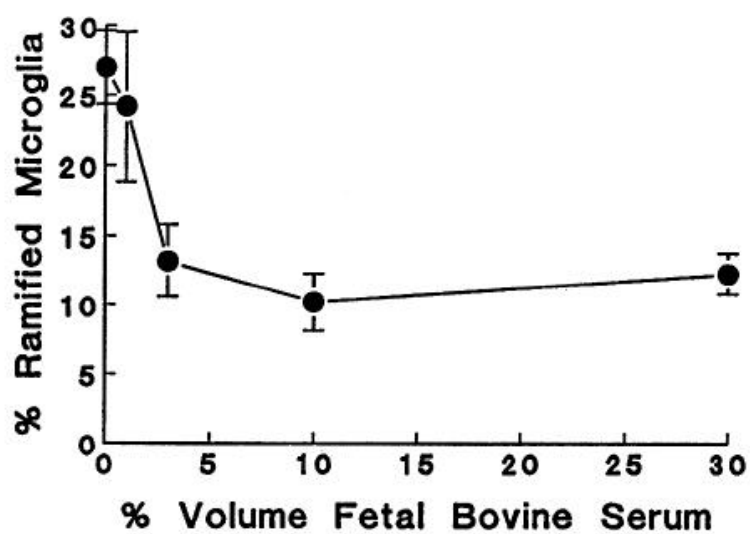

B

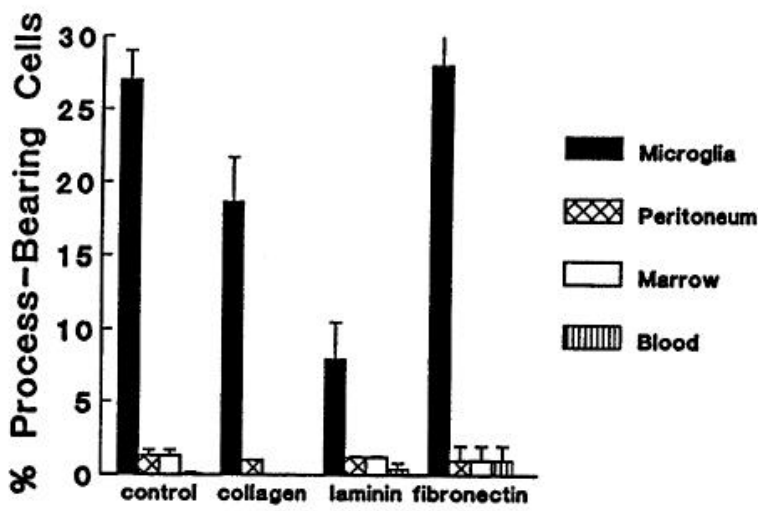

C

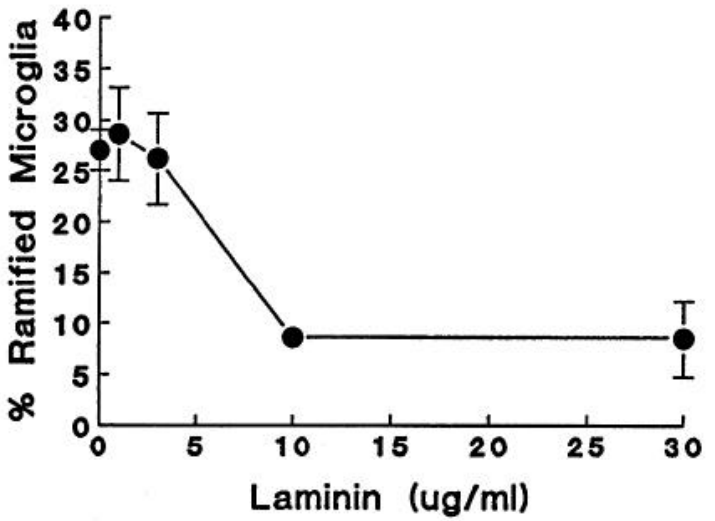

Figure 3. A, The presence of fetal bovine serum decreases the number of process-bearing microglia. $B$, Laminin $(100 \mu \mathrm{g} / \mathrm{ml})$ decreases the number of process-bearing microglia but has no effect upon other classes of mononuclear phagocytes. $C$, Laminin added to culture medium decreases the number of process-bearing microglia in a dose dependent fashion.
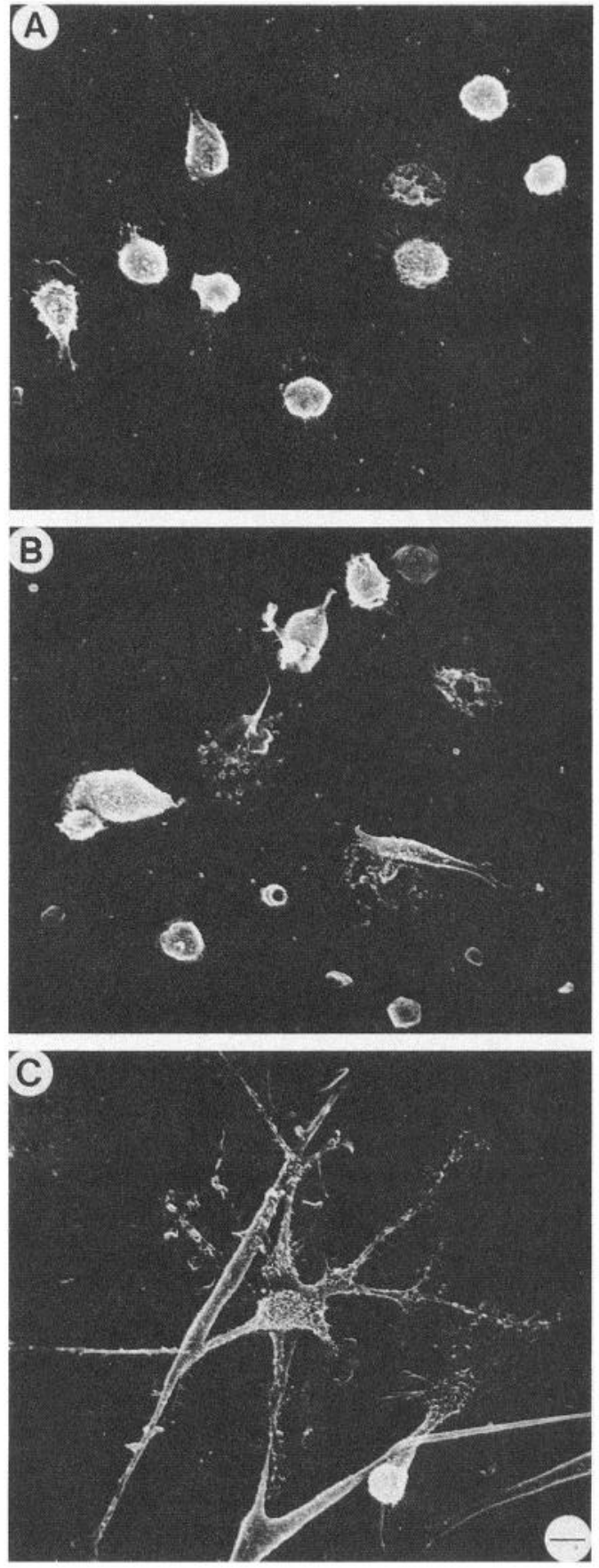

Figure 4. Scanning electron photomicrographs of mononuclear phagocytes exposed to 50 units of GM-CSF for $3 \mathrm{~d}$. As shown, there was no change in cell shapes for peritorreal macrophages $(A)$ and marrow cells $(B)$ while significant numbers of microglia become highly ramified (C). Scale bar, $5 \mu \mathrm{m}$.

with those of cells from other tissues of the newborn rat. During the first week in vitro, brain-derived microglia spontaneously proliferated while little cellular division was noted among mononuclear phagocytes from liver, spleen, peritoneum, or blood (Fig. 1). Bone marrow cells generally survived poorly in culture and did not proliferate in the absence of colony-stimulating factors. Within hours after plating, microglia underwent process formation while cells derived from bone marrow, liver, spleen, or peritoneum retained ameboid shapes (Fig. 2). By $3 \mathrm{~d}$ in culture, 25\% 

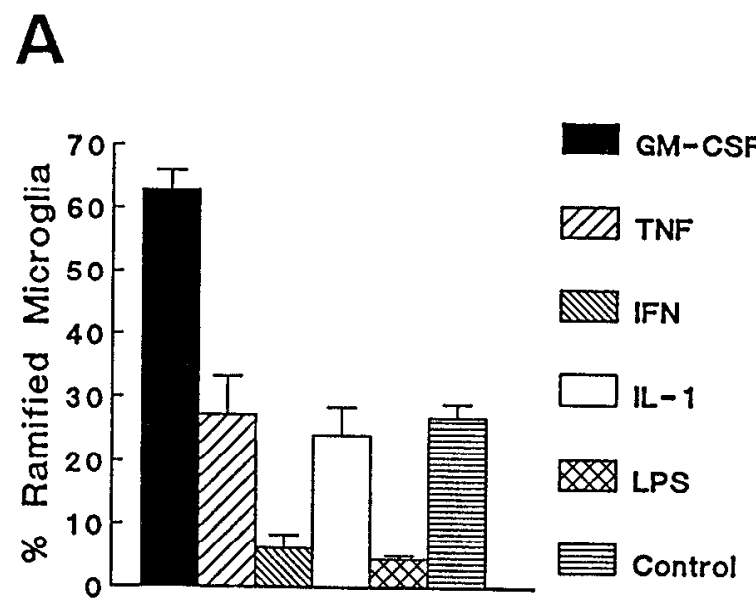

B
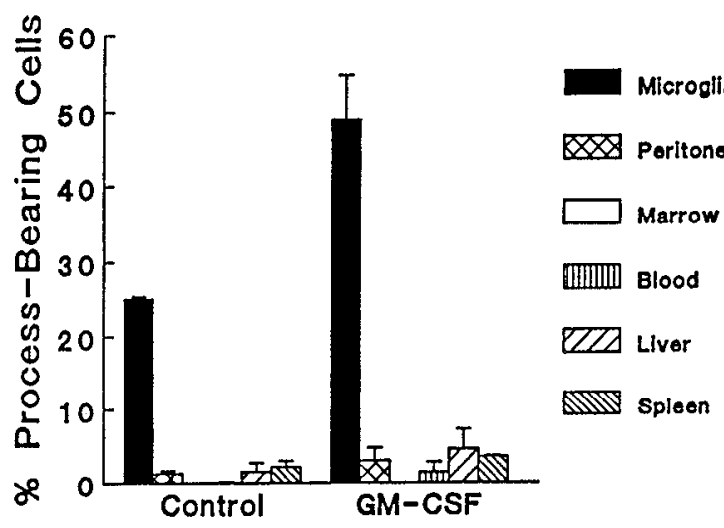

iindin Blood

Q72 Liver Spleen
C

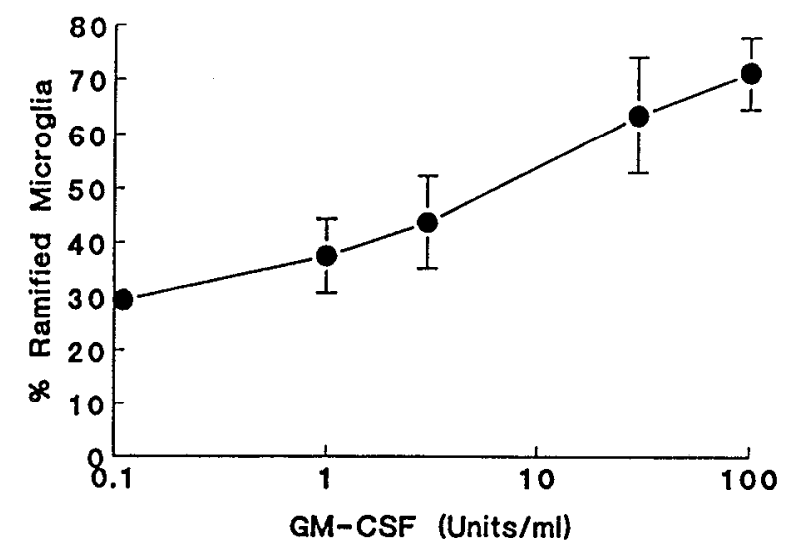

D

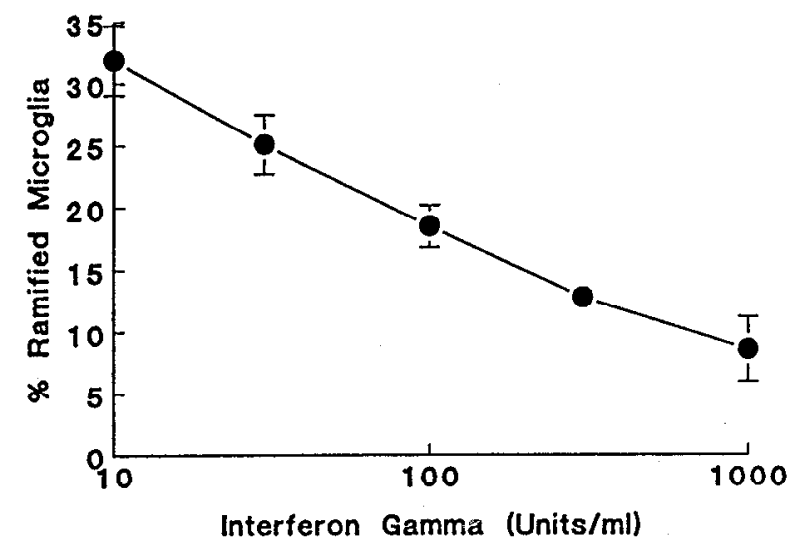

Microgita 5 Poritoneum

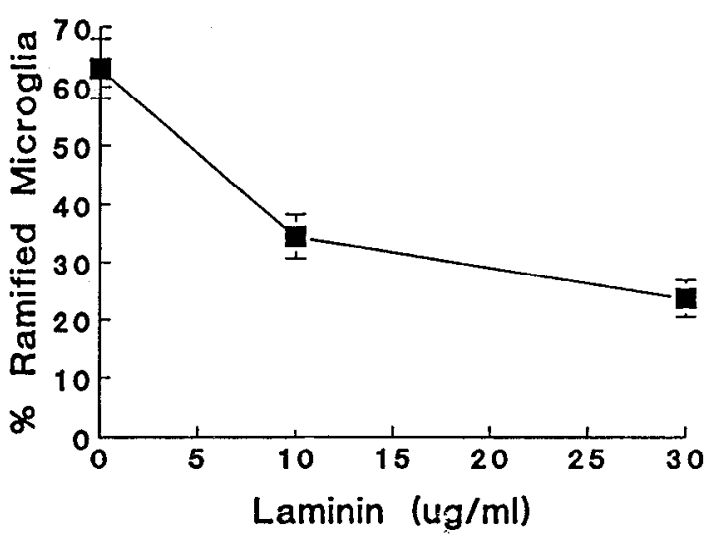

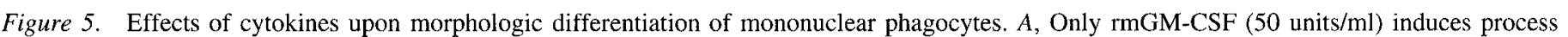

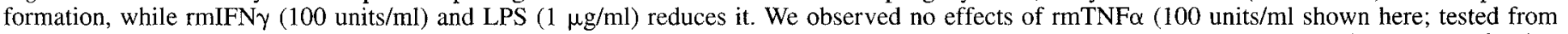

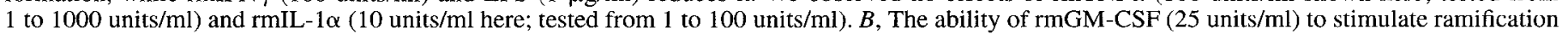

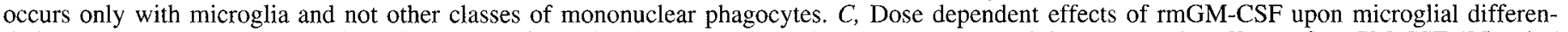

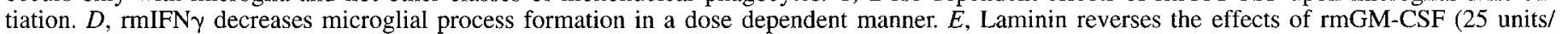
$\mathrm{ml}$ ) induced ramification.

of all microglia were ramified (defined as cells with process lengths more than three times the diameter of the cell body) compared with $<2 \%$ of the other tissue macrophages and none of the bone marrow-derived cells (Fig. 1). The mean process length for microglia of $100 \mu \mathrm{m}$ (Table 1) was far greater than that of macrophages and, in some cases, microglial branches reached beyond $500 \mu \mathrm{m}$. This pattern of process formation by microglia in culture paralleled the pattern of differentiation seen in tissues of maturing CNS as ameboid microglia transform into ramified cells (Rio-Hortega, 1932; Giulian et al., 1988; Ling and Wong, 1993). Cellular ramification in vitro thus serves as an anatomic marker for microglial differentiation. 


\section{Signals altering microglial differentiation}

We next considered what signals influence differentiation of brain mononuclear phagocytes. Spontaneous process formation by microglia was reduced after cells are exposed to fetal bovine serum; the serum blockade was dose dependent and occurred when cells were plated directly onto glass or plastic (Fig. 3A). We found that commonly used concentrations of serum (5\% to $10 \%$ ) had significant impact on the ability of isolated microglia to differentiate. Laminin, an extracellular matrix protein, added to culture media also markedly reduced microglial ramification (Fig. $3 B, C$ ), whereas other matrix proteins such as collagen and fibronectin had no effect (Fig. $3 B$ ). Of the battery of cytokines tested, only recombinant murine granulocyte macrophage colony-stimulating factor (rmGM-CSF) promoted microglial ramification, with $>65 \%$ of cells becoming process bearing (Figs. 4, 5) within $48 \mathrm{hr}$. This morphologic differentiation induced by rmGM-CSF was specific to microglia and not seen with tissue macrophages, marrow precursor cells, or blood monocytes (Figs. 4, 5). The mean length of microglial processes also increased by about twofold in the presence of rmGM-CSF (Table 1). On the other hand, activators known to promote microglial secretory activity, such as LPS and rmIFN $\gamma$, elicited ameboid shapes and retraction of processes (Fig. $5 A$ ) similar to the responses seen in tissue during reactive microgliosis. Cytokine regulation of microglial differentiation was dose dependent for both GM-CSF stimulation and rmIFN $\gamma$ suppression (Fig. 5C,D). Interestingly, laminin overcame the stimulatory effect of rmGM-CSF (Fig. $5 E$ ) suggesting that local deposits of extracellular matrix might moderate effects of cytokines upon microglial differentiation.

\section{Surface morphology of rat microglia}

Rio-Hortega (1932) first noted, using silver carbonate staining, that the surfaces of microglia possessed delicate spines. We also observed spines borne by fluorescently-labeled microglia in culture (Fig. 6) which were not apparent in other classes of mononuclear phagocytes. Further study by scanning electron photomicrographs revealed that microglial surfaces were, in fact, covered with spines as if protected by thorns (Fig. 7A). In contrast, the surfaces of bone marrow-derived mononuclear phagocytes were generally smooth (Fig. $7 B$ ) while tissue macrophages showed ruffling of membranes (Fig. $7 C$ ). Microglial spines were between 2 and $4 \mu \mathrm{m}$ in length with diameters of about $0.1 \mu \mathrm{m}$. In addition, microglia also contained thread-like-structures that extend several micrometers beyond the cell surface (Figs. 7D$F$ ). These threads arose from spines found on either microglial cell bodies or spines found on cell processes. Overall, microglial cellular projections (processes, spines, and thread-like networks) were strikingly different from the short, stubby processes of tissue macrophages. About $40 \%$ of these macrophages isolated from liver, spleen, or peritoneum of newborn rat had ruffled membranes, in contrast to $<3 \%$ of cells isolated from brain (Fig. $8 A$ ). Nearly $95 \%$ of microglia had $>20$ spines per cell (Fig. $8 B$ ) while about $98 \%$ of peritoneal macrophages show $<20$ spines per cell. The differences in surface features among microglia and other classes of cells persisted for at least $30 \mathrm{~d}$ in culture and were not affected by exposure to cytokines or immunostimulants (data not shown). Importantly, engulfment of particles such as zymosan did not obscure the spinous surfaces of phagocytic microglia (Figs. 8C,D).
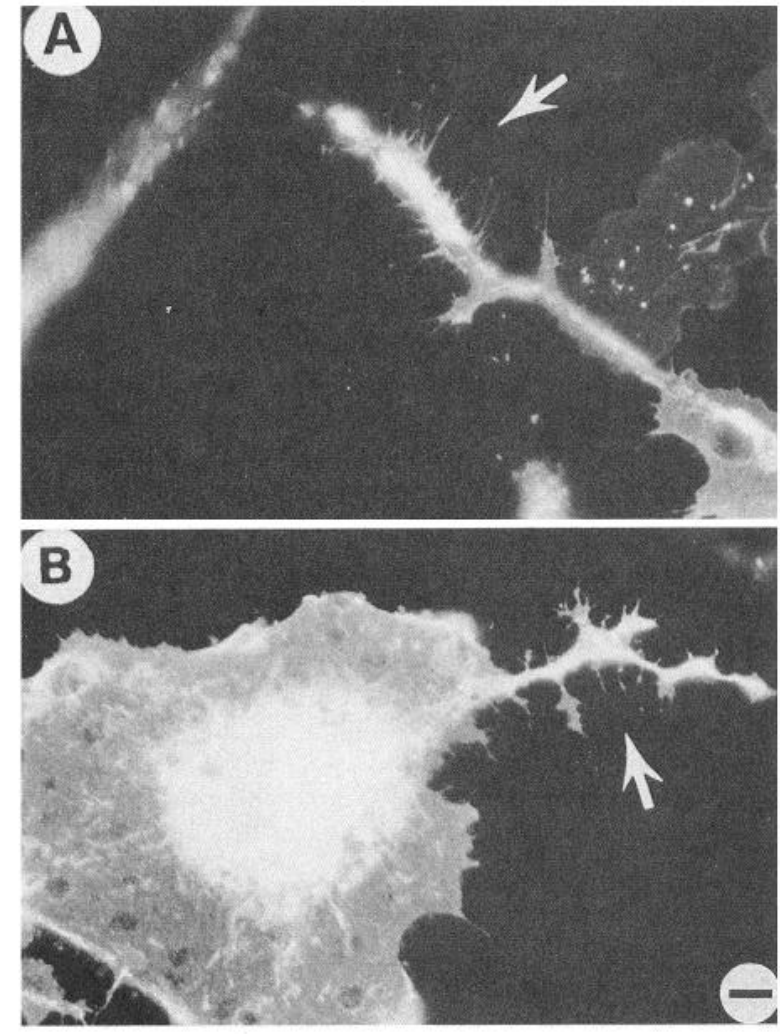

Figure 6. Fluorescence photomicrographs showing spines (arr which extend out from the surfaces of DiI-ac-LDL $(+)$ microglia. $\leqslant$ bar, $3 \mu \mathrm{m}$.

The spinous surface-a microglial marker for injured adult rat brain

To determine if surface characteristics could be used to identify microglia in later stages of development, we isolated mononuclear phagocytes from normal brain, spleen, and liver of adult rat. Nearly all adherent cells recovered from normal adult rat brain ( $>99 \%$ of cells recovered) were microglia-like with more than 20 spines per cell body and no ruffles (Fig. 9A). In contrast, liver macrophages showed ruffles ( $>90 \%$ of all cells) with few spinous surfaces (Fig. 9C). Only microglia were both ramified and spine-bearing. We went on to determine whether surface features could be used to distinguish types of mononuclear phagocytes cells appearing at sites of brain damage in adult rat. We isolated mononuclear phagocytes after inflicting different types of brain injury and compared the numbers of spine-bearing microglia to those of ruffled macrophages. As shown in Figure $10 C$, we recovered only microglia at sites of axonal degeneration (i.e., from optic tectum after optic nerve transection) while $30 \%$ of mononuclear cells isolated from brain damaged by stroke or trauma were ruffled macrophages (Fig. 9B). Moreover, reactive microglia from adult brain underwent ramification in culture while tissue macrophages did not (Figs. $10 A, B$ ). Thus, Rio-Hortega's description of microglia as cells with "wavy processes beset with spines" appeared to be an accurate and reliable way to distinguish microglia from blood-borne macrophages throughout postnatal development. In general, CNS insults producing local hemorrhage (such as stroke and penetrating trauma) recruited blood-borne macrophages, while distal injuries involving axonal degeneration elicited only reactive microglia (Kreutzberg and Barron, 1975; Hickey et al., 1992). 

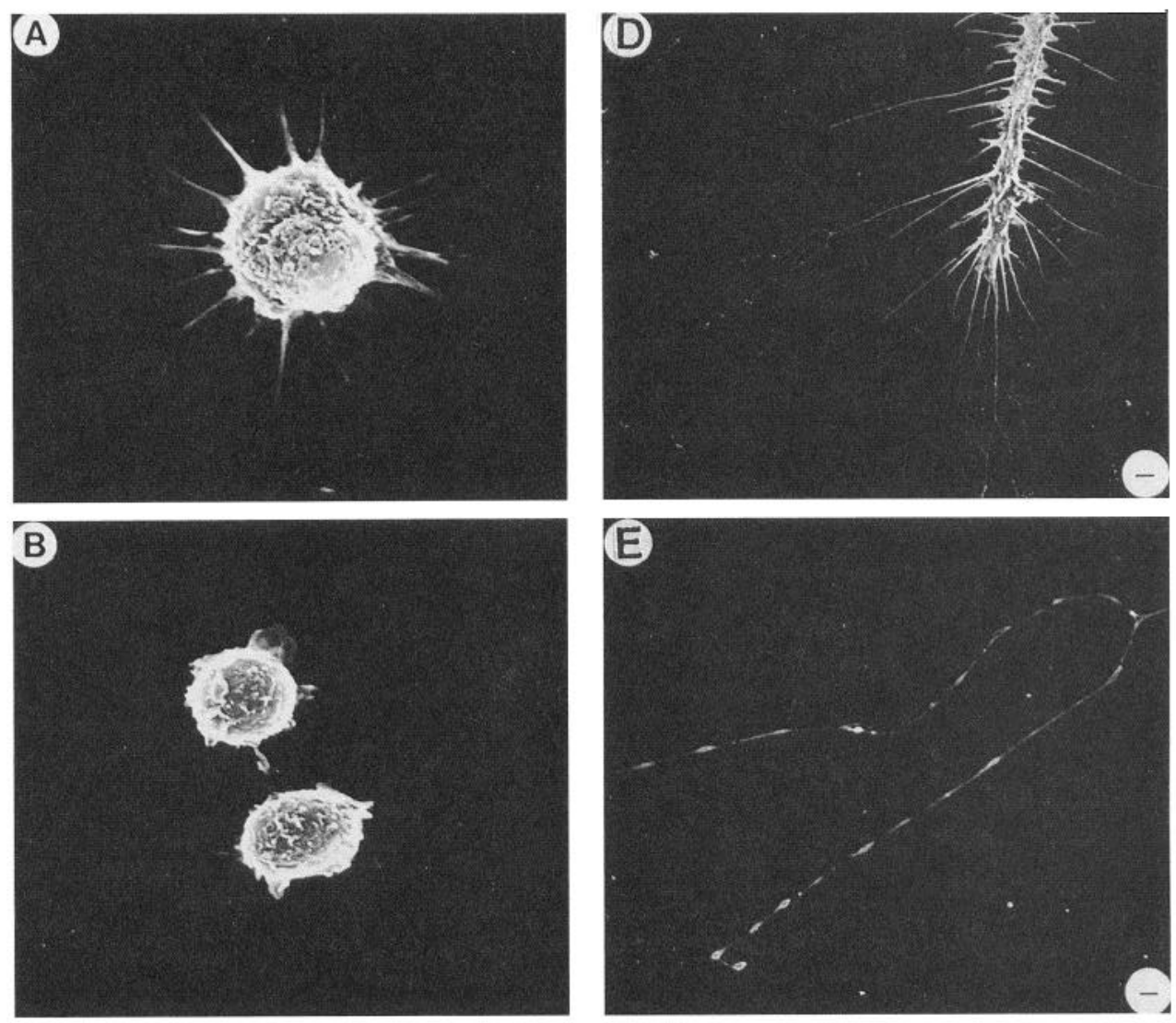

Figure 7. Scanning electron photomicrographs at high magnification showing the detail of mononuclear phagocytes. Microglia typically display 20 or more spines $(A)$ while blood monocytes have smooth surfaces $(B)$ and peritoneal macrophages have membrane ruffles $(C)$. Scale bar, $5 \mu \mathrm{m}$. $D$, Scanning electron photomicrograph of threadlike projection arising from microglial spines. Scale bar, $2.5 \mu \mathrm{m}$. $E$ and $F$, In addition to processes $(0.5 \mu \mathrm{m}$ diameter) and spines $(0.1 \mu \mathrm{m}$ diameters), the microglia cells demonstrate a delicate network of thread-like structures $(0.05$ $\mu \mathrm{m}$ diameters) which spread out beyond the cell's surface. Scale bar, $0.5 \mu \mathrm{m}$.
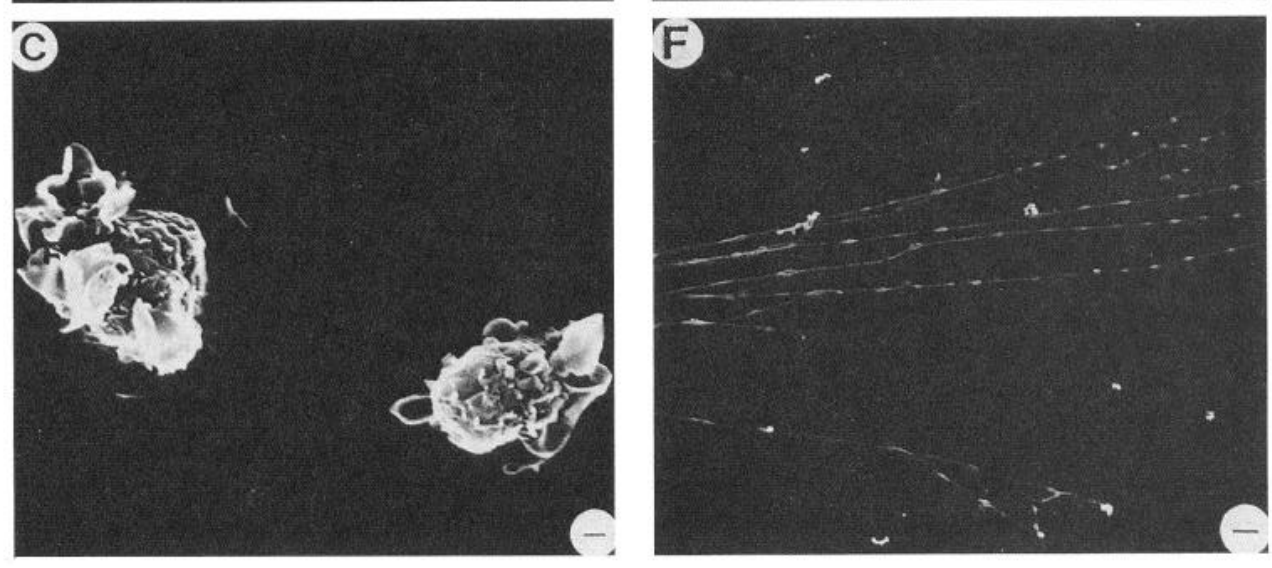

\section{Surface morphology of human microglia}

As noted above, the classes of reactive mononuclear phagocytes which appear within damaged brain depend upon the nature of the injury. This problem becomes more pressing in the study of human pathology since cell specific markers are not available to distinguish reactive microglia from macrophages. Accordingly, we applied cell surface criteria to cells isolated from human tissues within a $6 \mathrm{hr}$ post mortem interval. In a pattern similar to rat, we found recovered ruffled macrophages from human liver and from blood (Fig. 11E) and spine-bearing microglia from normal adult human brain (Fig. 11A). Human microglia developed processes in vitro as found for the rodent cells and these processes were covered with spines (Figs. $11 C, D$ ). Quantitation of such cells indicated that $>99 \%$ of mononuclear phagocytes recovered from normal human brain possessed spinous morphology $(99.0 \pm 0.3 \% ; n=300)$.

We extended these observations to neurologic diseases and compared cell types isolated from human brains known to contain reactive mononuclear phagocytes. Neocortical mononuclear cells found in amyotrophic lateral sclerosis (ALS) were essentially all spine-bearing microglia (Fig. 11D; Table 2) while significant numbers of ruffled macrophages were found in HIV-1 infected brains (Fig. $11 F$, Table 2). The patterns of appearance for these cell populations suggest that slow, degenerative disorders such as ALS recruit reactive resident microglia while HIV-1 infection involves compromised blood-brain barrier and increased trafficking of monocytes into the CNS (Flaris et al., 1993).

\section{Astroglial interactions with mononuclear phagocytes}

As described here, different classes of isolated mononuclear phagocytes behaved in distinct ways when grown in culture. It remained possible, however, that blood monocytes, bone marrow precursors, or tissue macrophages might take on features of microglia after exposure to a "brain environment." To determine, 


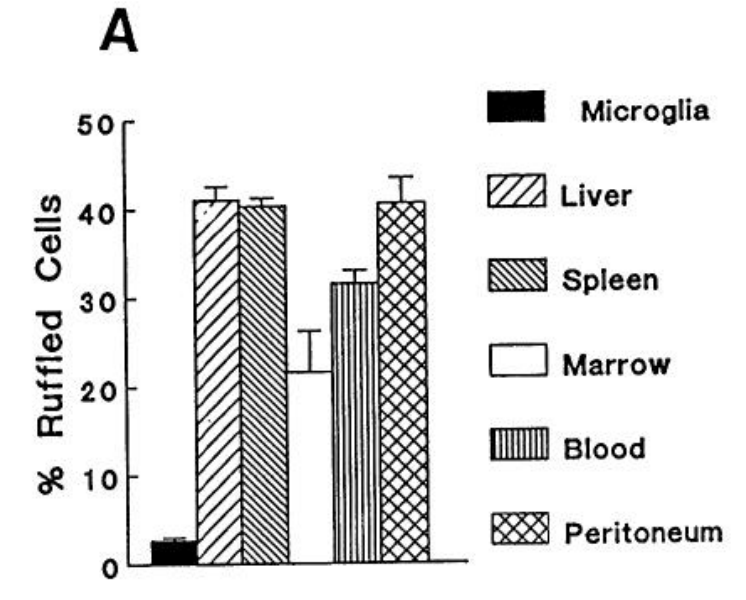

B

Microglia
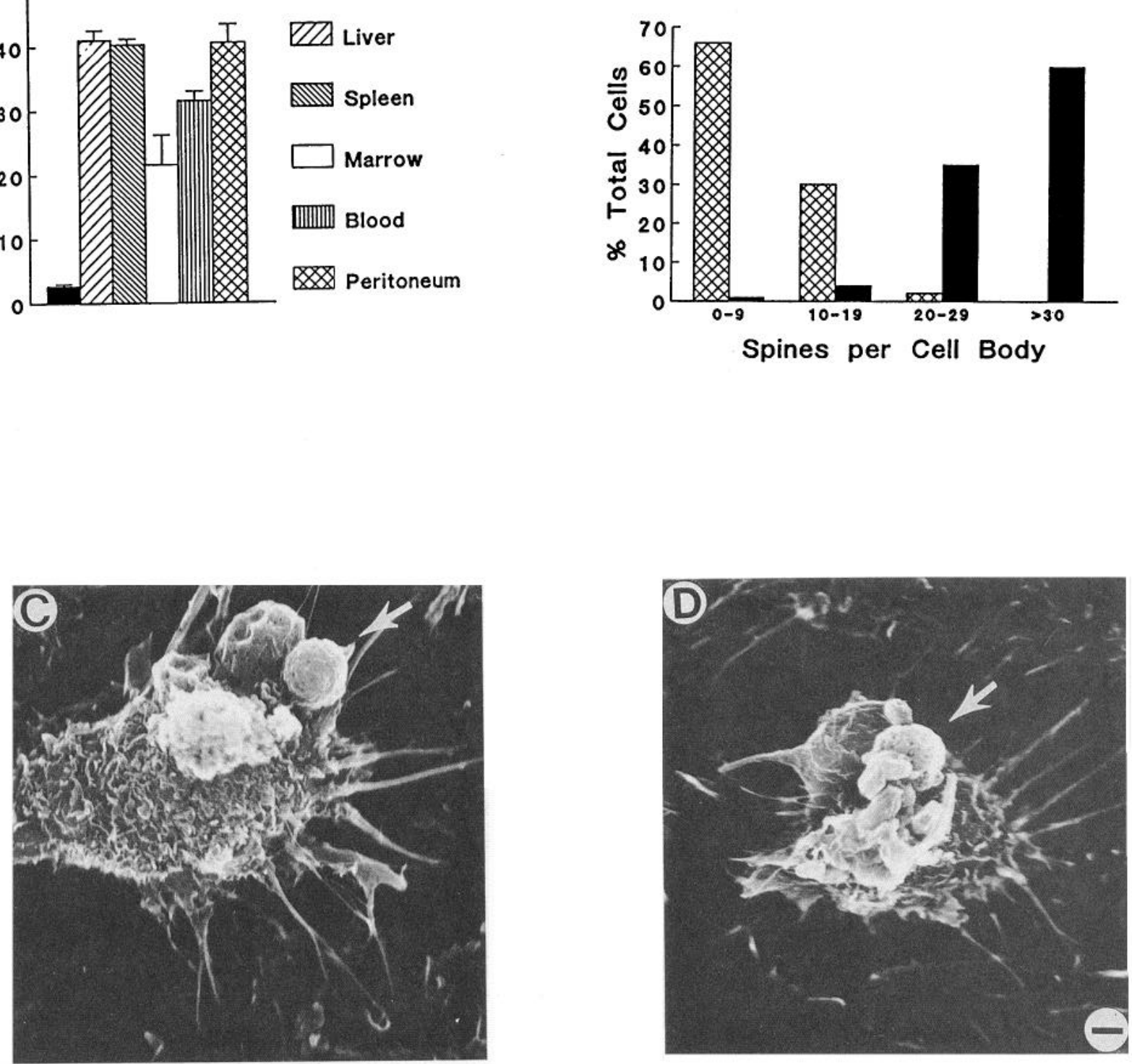

Figure 8. Surface morphological features for different classes of mononuclear phagocytes recovered from newborn rat. A, Microglia seldom show ruffled membranes in contrast to about $40 \%$ of tissue macrophages. $B$, Histogram shows the frequency of numbers of spines for microglia and liver macrophages. As shown, most macrophages have few , spines $(<10$ spines per cell) while $>95 \%$ microglia have 20 or more spines. $C$ and $D$, Scanning EM photomicrographs (at 3000 times magnification) show phagocytic microglia retain spinous surfaces as they engulf zymosan particles (arrows) of $1.5-2.0 \mu \mathrm{m}$ diameters.

whether other types of mononuclear phagocytes, particularly stem cells of the bone marrow, have the potential to become microglia, we carried out a series of coculture experiments involving astrocytes. Populations of mononuclear phagocytes isolated from different organs of the newborn rat were placed atop highly enriched populations of astroglia ( $>99 \%$ homogeneous). As shown by scanning EM, the presence of astroglia did not induce process formation nor did it change the surface morphology of blood monocytes (Fig. 12A), liver macrophages (Fig. 12B), splenic macrophages (Fig. 12C), or marrow-derived mononuclear phagocytes (Fig. 12D). Closer study by scanning EM demonstrated a persistence of microglial spines (Fig. 12E) while macrophage retained ruffled surfaces (Fig. 12F). Quantitative measures confirm that other classes of mononuclear phagocytes are unchanged (Table 3) despite prolonged contact with astroglia. With time, ramified microglia became so entangled with astrocytes that visualization of discrete cells by scanning EM was difficult. After $30 \mathrm{~d}$ in vitro, all microglia mixed among astrocytes had became highly ramified (Fig. 13B). In striking contrast, cultured tissue macrophages remained atop the feeder layers of astroglia and retained ameboid shapes for at least $30 \mathrm{~d}$ in vitro (Fig. 13A). Thus, despite prolonged exposure to brain glia, monocytes, macrophages, or marrow-derived cells (mononuclear phagocytes extrinsic to the CNS) did not take on properties of microglia.

To investigate further the nature of microglia-astroglia interactions, we examined either cell populations mixed in co-culture 

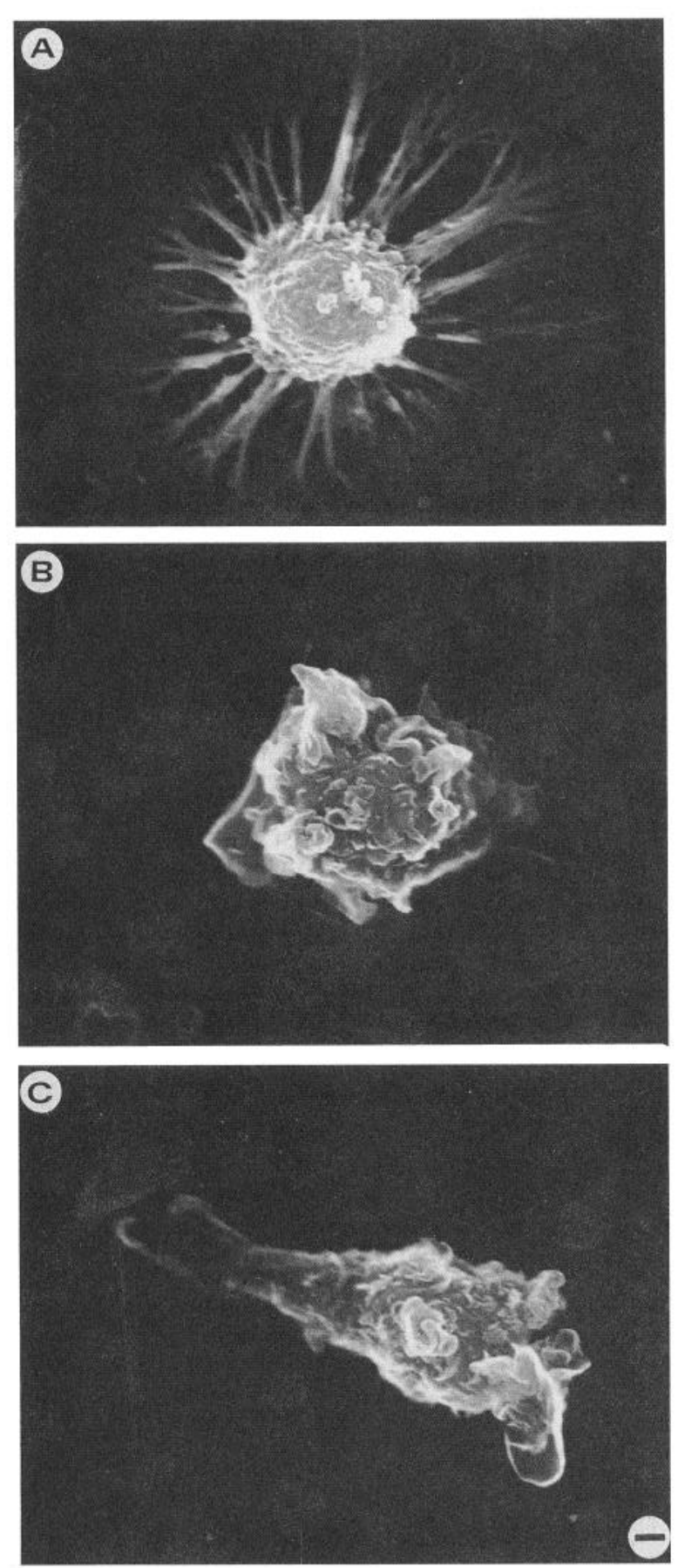

Figure 9. Microglia isolated from adult rat brain can be distinguished from tissue macrophages by scanning EM. As shown in $A$, nearly all microglia $(99 \%)$ isolated from normal adult brain contain numerous spines. In contrast, invading macrophages which appear in the brain 5 $\mathrm{d}$ after penetrating trauma $(B)$ or liver macrophages $(C)$ have ruffled surfaces with no spines. Scale bar, $5 \mu \mathrm{m}$.
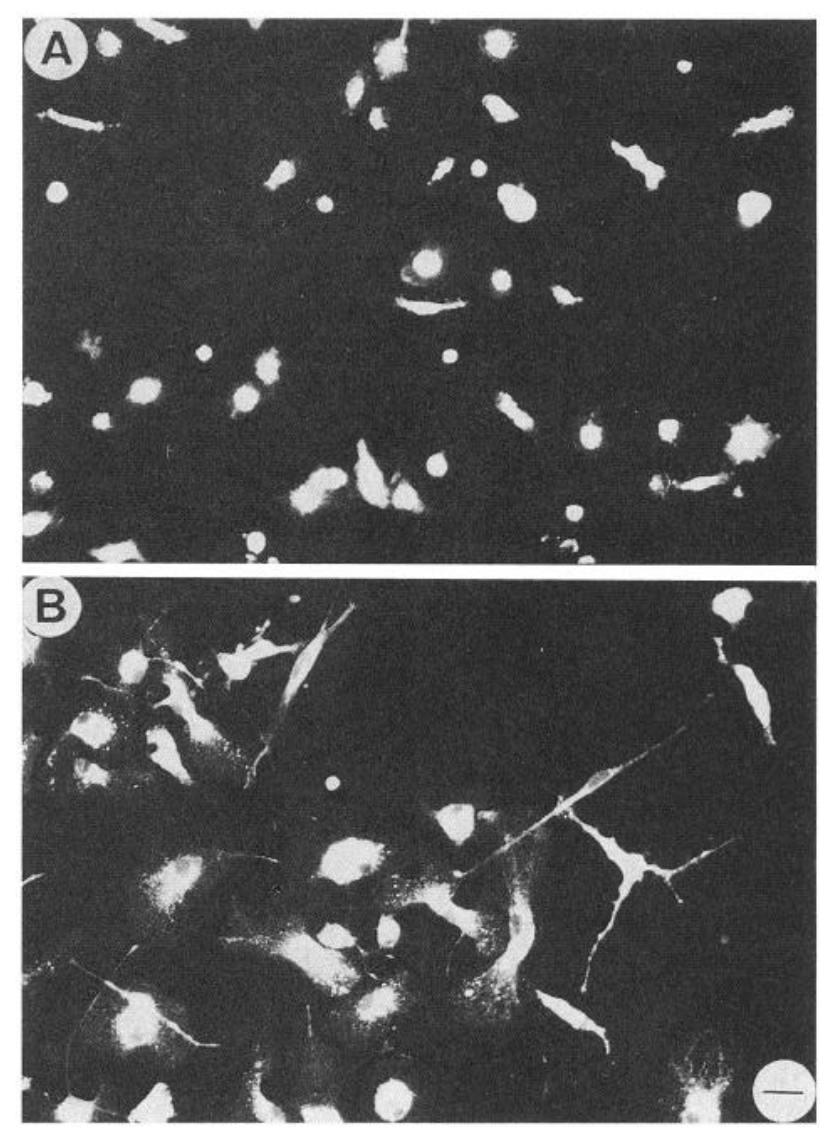

\section{C}

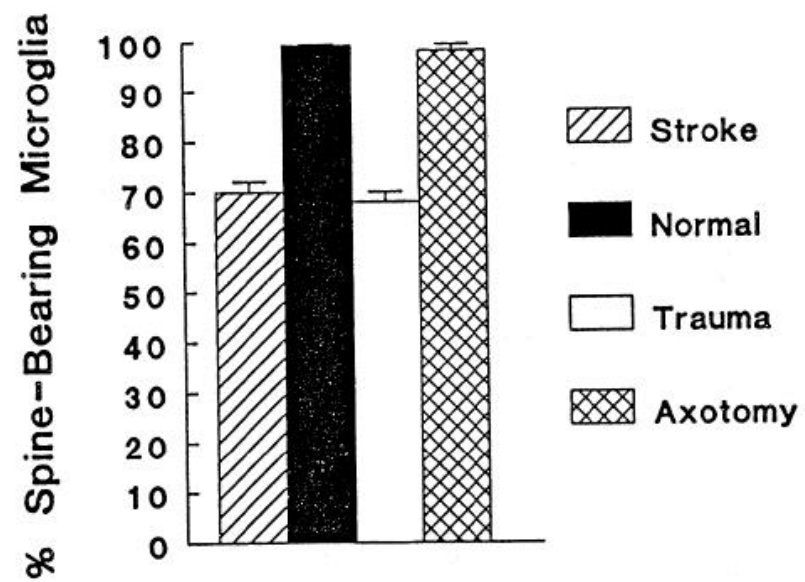

Figure 10. Reactive microglia recovered from axotomized adult optic tectum $(B)$ show process bearing cells which are clearly different from the liver macrophages shown in $A$. Scale bar, $20 \mu \mathrm{m}$. The histogram $(C)$ confirms that these populations of mononuclear phagocytes can be distinguished in adult tissues by scanning EM with $>99 \%$ microglia found in normal or axotomized tissue whereas about $30 \%$ of mononuclear cells isolated $5 \mathrm{~d}$ after ischemic or traumatic injuries to brain are invading macrophages with ruffled surfaces.

Figure 11. Scanning electron photomicrographs of mononuclear cells isolated from human brain after $3 \mathrm{~d}$ in culture. $A$, Nearly all cells recovered from normal adult brain are spine-bearing microglia. $B$, Human microglia from brains of patients with amyotrophic lateral sclerosis appear identical to those of normal brain. $C$, Adult human microglia underwent ramification in vitro with processes that are covered with spines $(D)$. $E$ ) Human blood monocytes in culture for $5 \mathrm{~d}$ take on the appearance of ruffled macrophages as noted for liver macrophages. $F$, At least $5 \%$ of cells recovered from HIV-1 infected brains of adults appear as ruffled macrophages. Scale bars: $A, B$, and $D, 1.2 \mu \mathrm{m} ; C, 7.0 \mu \mathrm{m} ; E$ and $F, 1.25 \mu \mathrm{m}$. 


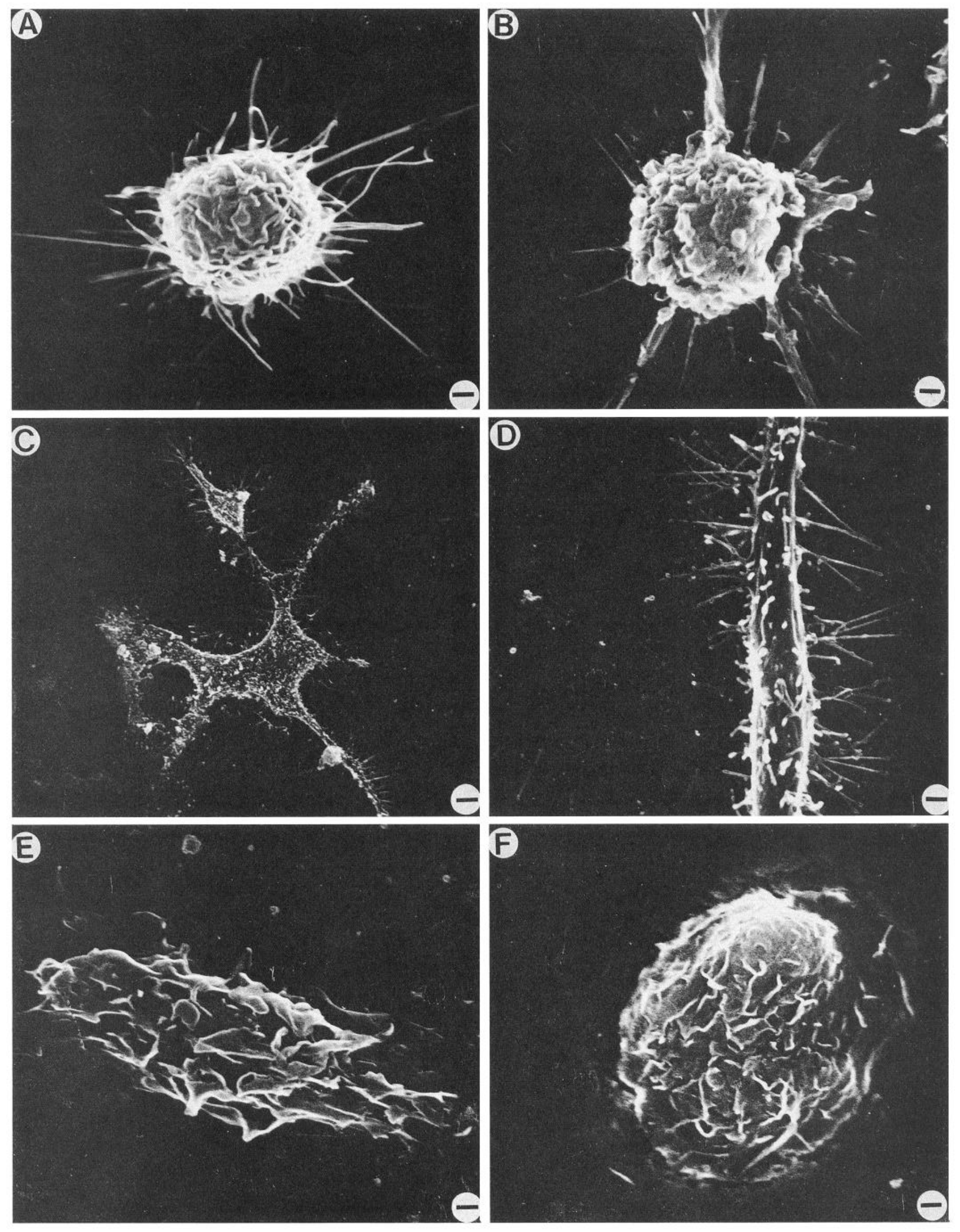



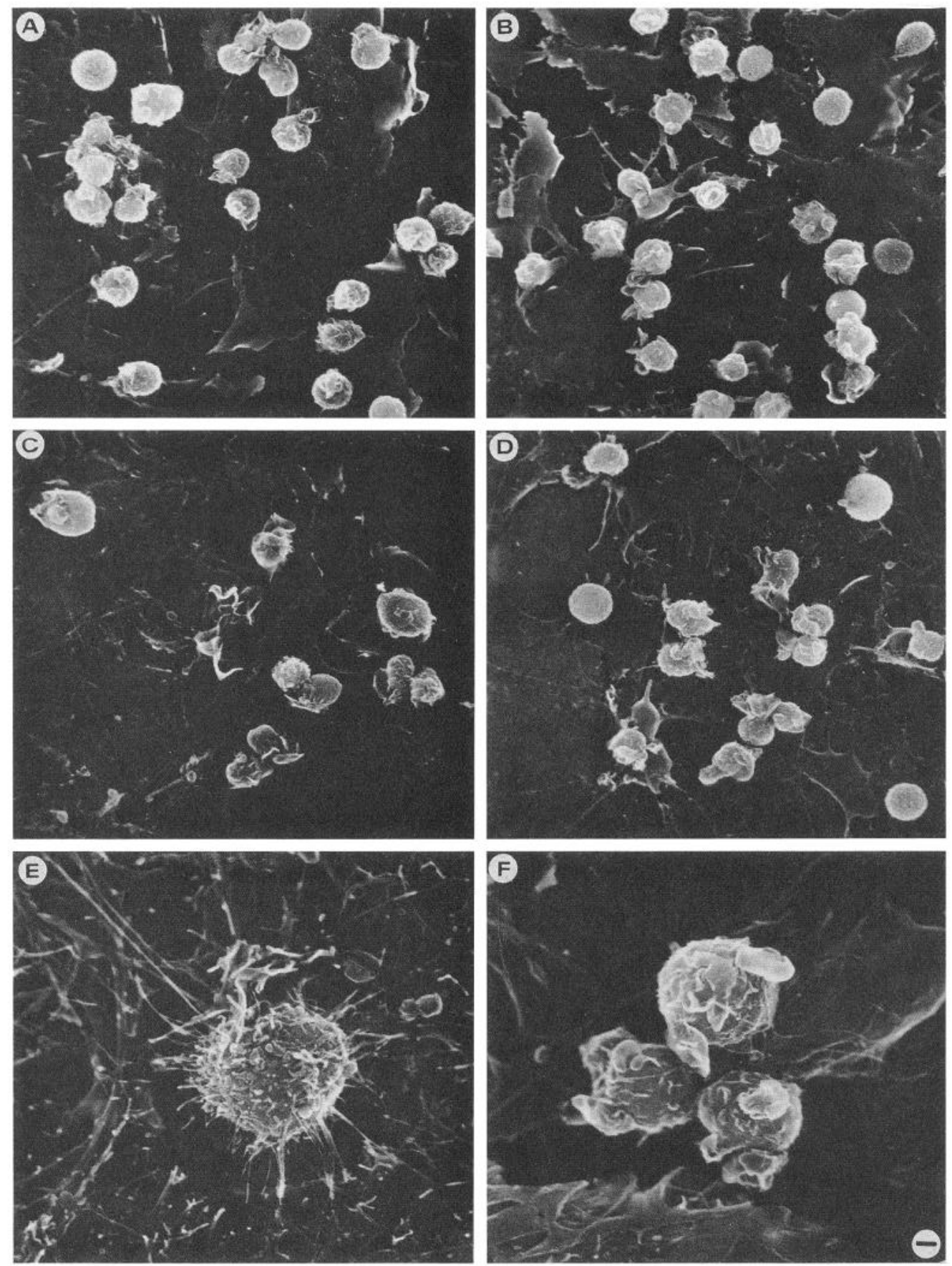

Figure 12. Scanning electron photographs of mononuclear phagocytes placed in coculture with astroglia for $7 \mathrm{~d}$. No process formation is noted for peritoneal macrophages $(A)$, marrow cells $(B)$, liver macrophages $(C)$, or spleen macrophages $(D)$. Scale bar, $5 \mu \mathrm{m}$. Microglia $(E)$ retain spine bearing surfaces while peritoneal macrophages show ruffled surfaces $(F$; scale bar, $0.5 \mu \mathrm{m})$.

or homogeneous cell populations physically separated from one another by filter-bottomed chambers. When isolated microglia were grown in $10 \%$ fetal bovine serum, we found $<10 \%$ of cells became ramified (Fig. 14A). As reported earlier (Giulian et al., 1991) mitogens released by astroglia (and found in media conditioned by astroglia or produced by astroglia grown in chambers) stimulated microglia to proliferate to give three- to fourfold increases in cell numbers (Fig. 14B,C,F). Astroglia-derived soluble factors did not, however, promote process formation. In contrast, direct contact between astroglia and microglia increased microg- lial ramification by nearly fivefold (Fig. 14D,F). Thus, contact with astroglia was necessary for microglia to undergo the accelerated differentiation observed. Since such astroglial contacts did not influence mononuclear cells recovered from outside the CNS (Fig. 13), it appears that astroglia exhibit a selective ability to promote and maintain microglia as ramified, quiescent cells.

\section{Discussion}

By exploiting a silver carbonate stain, Rio-Hortega (1932) was the first to identify microglia as a specific class of argentophilic 
Table 2. Mononuclear phagocytes isolated from human brain

$\%$ Ruffled macrophages

\begin{tabular}{ll}
\hline Normal & $0.3 \pm 0.3$ \\
ALS & $0.7 \pm 0.5$ \\
HIV-1 & $5.3 \pm 1.3 * *$
\end{tabular}

Randomly selected mononuclear cells isolated from human brains within a 6 $\mathrm{hr}$ post-mortem interval were monitored for the presence of ruffled macrophages. Nearly all cells cultured from normal adult brain as well as cells from brains with amyotrophic lateral sclerosis (ALS) were spine-bearing microglia. However, HIV-1 infected adult brain contained a significant increase in the number of ruffled macrophages when compared to normal brain $(* *$, Student's test $=3.74, \mathrm{df}=598 ; p<0.0002$ ). Data are expressed as percentages \pm SEM based upon 300 cells randomly selected from each diagnostic category.

brain cell with two or more branched processes and spines. RioHortega further described microglia during embryonic development as ameboid cells showing such macrophagic properties as migratory capacity and phagocytosis. During CNS injury, ramified microglia retract processes, become more ameboid-like, and transform into a third form, the reactive microglia (RioHortega and Penfield, 1927). After Rio-Hortega, the art of silver carbonate staining, and thus the ability to identify microglia, was lost. Many investigators came to believe that microglia were simply blood monocytes invading acutely injured tissue and not a distinct class of brain cells (Konigsmark and Sidman, 1963; Perry et al., 1985). This problem has been compounded by contradictory reports on the presence or absence of macrophage cell markers as viewed by histological study of brain tissues taken from different stages of development or CNS injury (Wood et al., 1976; Ling et al., 1982). Currently, there are no unique histochemical markers that distinguish activated or ameboid microglia from invading brain macrophages (Flaris et al., 1993; Ulvestad et al., 1994). This inability to distinguish cell types has led to much confusion regarding the presence and function of microglia in brain pathology.

As described here, microglia cultured from postnatal brain possessed specific characteristics indicating this cell population to be a distinct class of mononuclear phagocyte. We found, for example, that microglia of rat showed proliferative capacity, patterns of differentiation, surface morphologies, responses to cytokines, and interactions with astrocytes that were clearly different from macrophages of spleen, liver, and peritoneum, from monocytes of blood, and from bone-marrow derived stem cells. Importantly, these differences persisted into adulthood such that spine-bearing microglia were readily distinguished from ruffled macrophages by scanning EM. Scanning EM provided, moreover, a method to distinguish invading macrophages from resident microglia at CNS sites of trauma, stroke, and axonal degeneration. The types of inflammatory cells identified by scanning EM in such models of brain injury generally agree with the descriptions from other laboratories using bone marrow chimeras (Hickey and Kimura, 1988; Hickey et al., 1992; Flaris et al., 1993). Our data suggest that CNS injury which produced local hemorrhage gave rise to macrophage invasion of the brain whereas distal axotomy elicited only reactive microgliosis.

The lack of unique microglia identifiers has been a limiting factor when assessing types of inflammation in human brain pathology. A growing body of evidence now shows that cytokines and cytotoxins released by reactive mononuclear phagocytes after brain injury will influence survival of neurons (Giulian, 1992; Giulian et al., 1995). However, the origin of these acti-
Table 3. Morphology of mononuclear phagocytes in culture with astrocytes

\begin{tabular}{lrrrrr} 
& Peritoneum & \multicolumn{1}{c}{ Spleen } & \multicolumn{1}{c}{ Liver } & Marrow & Microglia \\
\hline \% Ruffled & $62 \pm 3$ & $58 \pm 2$ & $46 \pm 2$ & $21 \pm 4$ & $6 \pm 1$ \\
\% Spinous & $0 \pm 0$ & $0 \pm 0$ & $0 \pm 0$ & $0 \pm 0$ & $94 \pm 1$ \\
\% Smooth & $38 \pm 2$ & $41 \pm 2$ & $54 \pm 3$ & $78 \pm 4$ & $0 \pm 1$ \\
\% Branched & $1 \pm 1$ & $1 \pm 1$ & $2 \pm 1$ & $0 \pm 0$ & $57 \pm 3$
\end{tabular}

Features for different classes of mononuclear phagocytes placed in coculture with astroglia for $7 \mathrm{~d}$. Microglia properties such as branching (defined as cells with process lengths $>3 \times$ diameter of cell body) and spinous surfaces (defined as $>20$ spines per cell) were not detected in other classes of mononuclear phagocytes, all of which maintained a ruffled surface morphology despite contact with astroglia.

vated mononuclear brain cells might be quite different- the result of either trafficking of blood monocytes across the blood brain barrier or the recruitment of quiescent resident microglia. Our finding that cell surface features viewed by scanning EM can distinguish human microglia from invading macrophages provides a new method for classification of brain inflammatory responses. As described here, ALS is one type of neurodegenerative disorder which does not involve blood cell invasion. In contrast, recovery of significant number of macrophages from
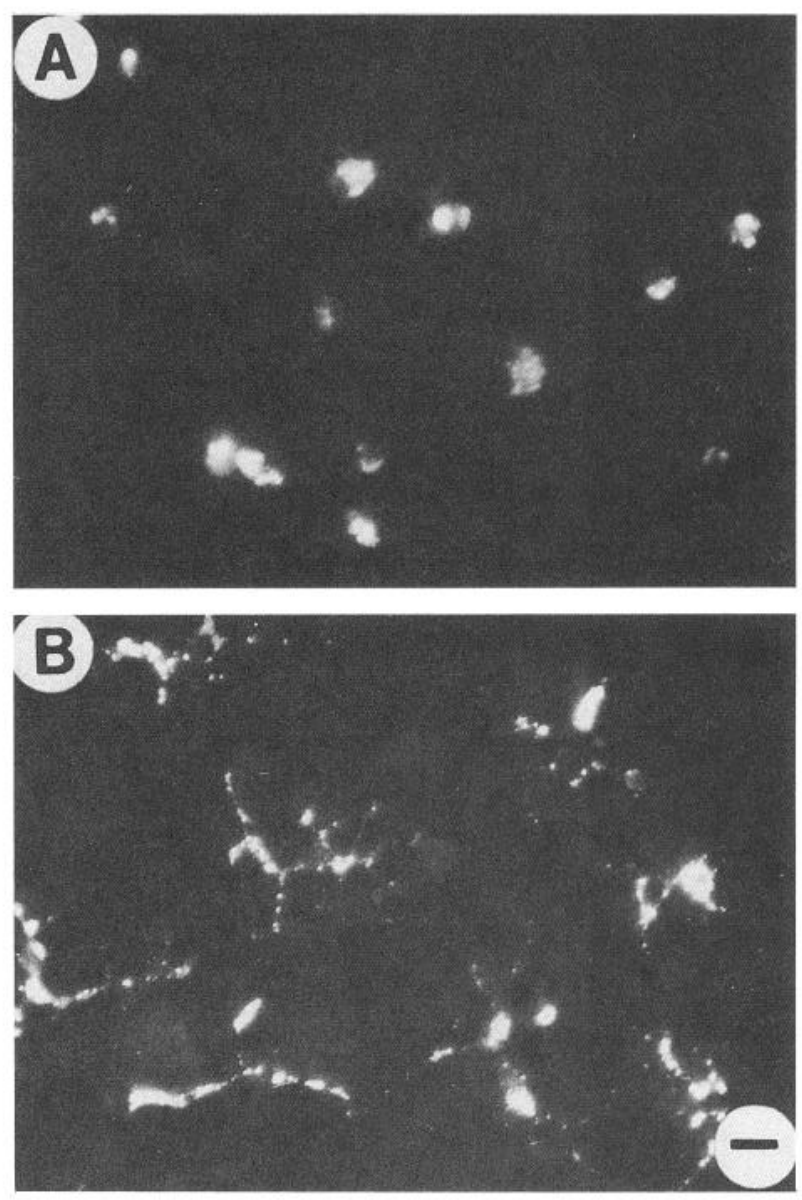

Figure 13. Fluorescence photomicrographs of mononuclear phagocytes after $30 \mathrm{~d}$ in contact with astroglia DiI-ac-LDL(+) liver macrophages persist atop feeder layers of astroglia and retain ameboid shapes $(A)$. In contrast, all microglia undergo differentiation with striking process formation $(B)$. These cells intertwine with astroglial processes and integrate within the brain environment. Scale bar, $20 \mu \mathrm{m}$. 

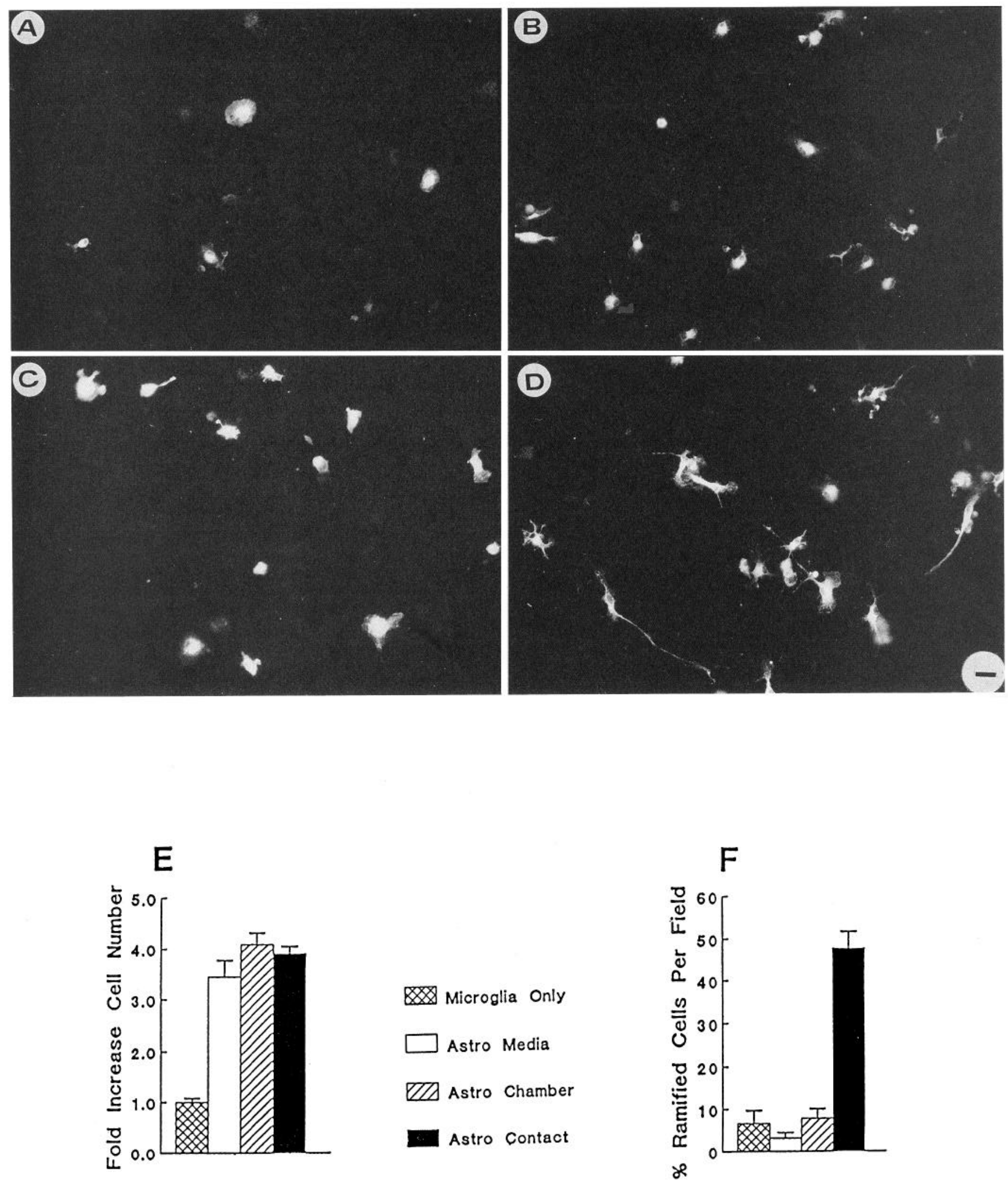

Figure 14. Fluorescence photomicrographs of DiI-ac-LDL(+) microglia after exposure to astroglia. All microglia were grown at low density in the presence of fetal bovine serum. Microglia control cultures were grown in the absence of astrocytes (Microglial Only; A) or in the presence of astroglia but separated by filtered bottom chambers (Astro Chamber; B). There is an increase in cell number (mitogenic effect) but no effect upon process formation. Microglia exposed to $30 \%$ culture media conditioned by astrocytes (Astroglial CM; $C$ ) also shows an increase in cell number but not process formation. When in direct contact with astroglia, microglia both increase in number and increase in process formation (Astro Contact; $D$, scale bar, $20 \mu \mathrm{m}$ ). Quantitative measurements of different coculture conditions indicate that astroglia-contacts promote microglia differentiation $(F)$ whereas secreted astroglial factors were mitogenic ( $E$; see Giulian et al., 1991). Neither mitogenic nor differentiation effects were noted with other classes of mononuclear phagocytes placed in culture with astroglia. 
HIV - 1 infected brain points to another type of pathology with an altered flow of blood-borne cells into the CNS. Further studies employing morphological markers may help to delineate the subpopulations, locations, and neurotoxic capacities of viral infected cells within the brain.

Microglia could be distinguished from bone marrow-derived mononuclear cells, which have been considered the peripheral precursor cells for adult brain microglia. For example, under the culture conditions used here, only microglia showed spontaneous mitosis, while the precursor cells of hone marrow survive poorly. To determine if a "brain cell environment" altered morphologies of mononuclear phagocytes, we placed cells in coculture among highly enriched populations of astrocytes. Microglia established complex branches that entwined astroglial processes while bone marrow cells retained ameboid shapes and did not interact with astroglia. Although it has long been proposed that bone marrow-derived stem cells were a source of microglia, we found no in vitro evidence that postnatal marrowderived cells transform into microglia. Such observations are consistent with the in vivo findings of Hickey and Kimura (1988) in which no exchange between blood cells and parenchymal microglia occurred in normal adult brain. In view of the fact that the survival or proliferation of bone marrow cells, unlike microglia, were not in any way influenced by astroglia, we conclude that microglia are uniquely adapted to the CNS. Perhaps primitive stem cells common to microglia of the CNS and to macrophages of other organs exist - but only during early prenatal development. Our observations contrast a recent report by Sievers et al. (1994) which describes the appearance of processbearing cells after blood monocytes are added to heterogeneous cultures of brain glia. Through mixing experiments (coculture with different strains of murine cells or exposure of human monocytes to rat astrocytes) these authors conclude that blood monocytes take on microglia-like shapes when exposed to astrocytes. Further work using more carefully controlled in vitro conditions and selective cell markers will be needed to compare the monocyte-astrocyte interactions reported here with those seen in culture systems described by Sievers et al. (1994).

In order to organize and maintain a distinct population of mononuclear cells within the CNS, specific signals must act upon developing microglia to induce cells to mature and grasp the tissues of the brain. In general, we found that the number and length of processes formed by microglia in vitro were dependent upon the culture environment. Fetal bovine serum, for example, substantially inhibited microglia from forming processes, as did laminin. Immuno-activators such as LPS and rmIFN $\gamma$ drove microglia to retract processes whereas such cytokines as rmIL-1 $\alpha$ and rmTNF $\alpha$ did not alter microglial shapes. Although both microglia and bone marrow-derived cells proliferated in response to $\mathrm{rmGM-CSF}$, only microglia underwent cytokine-induced ramification. The GM-CSF released by brain tissues during early postnatal development (Giulian et al., 1991) might promote microglial populations to mature and, thus, serve as an endogenous regulator of microglial differentiation.

Why are differences in the behaviors of microglia and macrophages important? Unlike other tissues, the mature CNS demonstrates an immune "privilege" which reflects, in part, the fact that adult brain is populated by a quiescent class of mononuclear phagocytes. Quiescent microglia, with marked reduction in MHC class II expression, reduced capacity to present antigen, and limited secretory function, are in marked contrast to the active phagocytic macrophages (Giulian, 1992) which guard the peritoneum, gut, liver, spleen, and lung. We suggest that astroglial contacts help to maintain microglia in a differentiated, quiescent state in order to restrict such microglial capacities as synaptic stripping (Blizinger and Kreutzberg, 1965) and release of neurotoxins (Giulian et al., 1993). Thus, astroglia provide a stabilizing influence upon microglia to reduce the likelihood of immune attack upon neurons. This dampened microglial response might protect brain from disruptive effects of immunoregulators produced during systemic immune activation and might be one reason the CNS rejects tissue transplants slowly (Medawar, 1947). Through such inhibitory mechanisms, the potentially disruptive activities of reactive microglia are narrowly limited by astrocytes to specific sites and locations of injured brain.

Microgha have distinctive morphologies and behaviors in culture when compared to cells from spleen, liver, peritoneum, blood monocytes, and marrow. The surface features seen by scanning EM distinguish microglia from populations of all types of tissue macrophages in the postnatal animal. Importantly, microglia respond differently to contact with astroglia by undergoing differentiation. Despite testing a variety of culture conditions, we did not find any evidence that brain provides an environment to transform macrophages, monocytes, or primitive marrow cells of postnatal rat into microglia. Cultured microglia eventually transform into quiescent cells, as observed in vivo, with reduction of surface receptors, loss of phagocytic activity, and reduced secretory activity (data not shown). Reactivation of ramified microglia involves the upregulation of surface receptors in these cells, the reappearance of secretory capacity, and new migratory activity - all necessary as microglia engage in neurotoxic or wound healing behaviors described in a variety of disorders including stroke, trauma, HIV-1 infection, and $\mathrm{Al}-$ zheimer's disease. Chronic microgliosis may depend, therefore, upon the persistence of activating signals and the nature of microglia-astroglia interactions.

\section{References}

Banati RB, Gehrmann J, Schubert P, Kreutzberg GW (1993) Cytotoxicity of microglia. Glia 7:111-118.

Blinzinger K, Kreutzberg G (1968) Displacement of synaptic terminals from regenerating motoneurons by microglial cells. Z Zellforschung 85:145-157.

Boje KM, Arora PK (1992) Microglial-produced nitric oxide and reactive nitrogen oxides mediate neuronal cell death. Brain Res 587: 250256

Bolsi D (1927) Placche senile e microglia. Riv Patol Nerv Mental 32: $65-74$.

Bottenstein JE, Sato GH (1979) Growth of a rat neuroblastoma cell line in serum-free supplemented medium. Proc Natl Acad Sci USA 76:514-517.

Boya J, Carbonell AL, Calvo J, Borregon A (1987) Ultrastuctural study on the origin of rat microglia cells. Acta Anat 130:329-335.

Boyum A (1968) Isolation of leucocytes from human blood. A twophase system for removal of red cells with methylcellulose as erythrocyte-aggregating agent. Scand J Clin Lab Invest Suppl 97:9-29.

Daems WT (1980) Peritoneal macrophages. In: The reticuloendothelial system (Carr I, Daems WT, eds), pp 57-127. New York: Plenum.

Flaris NA, Densmore TL, Molleston MC, Hickey WF (1993) Characterization of microglia and macrophages in the central nervous system of rats: definition of the differential expression of molecules using standard and novel monoclonal antibodies in normal CNS and in four models of parenchymal reaction. Glia 7:34-40.

Giulian D (1987) Ameboid microglia as effectors of inflammation in the central nervous system. J Neurosci Res 18:155-171.

Giulian D, Baker TJ (1986) Characterization of ameboid microglia isolated from developing mammalian brain. J Neurosci 6:2163-2178. 
Giulian D, Lachman LR (1985) Interleukin-1 stimulation of astroglial proliferation after brain injury. Science 228:497-499.

Giulian D, Woodward J, Young D, Krebs JF, Lachman LB (1988) Interleukin-1 injected into mammalian brain stimulates astrogliosis and neovascularization. J Neurosci 5:2485-2490.

Giulian D, Chen J, Ingeman JE, George J, Noponen M (1989) The role of mononuclear phagocytes in wound healing after traumatic injury to adult mammalian brain. $J$ Neurosci 9:4416-4429.

Giulian D, Robertson C (1990) Inhibition of mononuclear phagocytes reduces ischemic injury in the spinal cord. Ann Neurol 27:33-42.

Giulian D, Vaca K, Noonan CA (1990) Secretion of neurotoxins by mononuclear phagocytes infected with HIV-1. Science 250:15931596.

Giulian D, Johnson B, Krebs JF, George JK, Tapscott M (1991) Microglial mitogens are produced in the developing and injured mammalian brain. J Cell Biol 112:323-333.

Giulian D (1992) Microglia and diseases of the nervous system. Curr Neurol 12:23-54.

Giulian D, Corpuz M, Chapman S, Mansouri M, Robertson C (1993) Reactive mononuclear phagocytes release neuron killing factors after stroke and trauma, J Neurosci Res 25:227-233.

Giulian D, Vaca K, Corpuz M (1993) Brain glia release factors with opposing actions upon neuronal survival. J Neurosci 13:29-37.

Giulian D, Haverkamp LJ, Li J, Karshin WL, Yu J, Tom D, Li X, Kirkpatrick JB (1995) Senile plaques stimulate microglia to release a neurontoxin found in Alzheimer's brain. Neurochem Int 27:119137.

Graeber MB, Tetzlaff W, Streit WJ, Kreutzberg GW (1988) Microglia cells but not astrocytes undergo mitosis following rat facial nerve axotomy. Neurosci Lett 85:317-321.

Hetier E, Ayala J, Bousseau A, Denefle P, Prochiantz A (1990) Amoeboid microglial cells and not astrocytes synthesize TNF $\alpha$ in Swiss mouse brain cell cultures. Eur J Neurosci 2:762-768.

Hickey WF, Kimura H (1988) Perivascular microglial cells of the CNS are bone marrow-derived and present antigen in vivo. Science 239: 290-292.

Hickey WF, Vass K, Lassmann H (1992) Bone marrow-derived elements in the central nervous system: an immunohistochemical and ultrastructural survey of rat chimeras. J Neuropathol Exp Neurol 51: 246-256.

Higgins GA, Olschowka JA (1991) Induction of interleukin-1ß mRNA in adult rat brain. Mol Brain Res 9:143-148.

Hsu CY, Yong YH, Ping-Keung Y, Luk YO, Chen ST, Hogan ET (1990) A stroke model designed for preclinical trial. In: Cerebral ischemia and resuscitation (Surr A, Rigor BM, eds), pp 47-59. Boca Raton: CRC.

Imamoto K, Leblond CP (1977) Presence of labeled monoctyes, macrophages, and microglia in a stab wound of the brain following an injection of bone marrow cells labeled with ${ }^{3} \mathrm{H}$-uridine into rats. $\mathbf{J}$ Comp Neurol 174:255-280.

Jordan FL, Thomas WE (1988) Brain macrophages: questions of origin and interrelationship. Brain Res 472:165-178.

Kettenmann H, Hoppe D, Gottmann K, Banati R, Kreutzberg G (1990) Cultured microglial cells have a distinct pattern of membrane channels different from peritoneal macrophages. J Neurosci Res 26:278287.

Konigsmark BW, Sidman RL (1963) Origin of brain macrophage in mouse. J Neuropathol 22:643-676.
Koski IR, Poplack DG, Blaese RM (1976) A nonspecific esterase stain for the identification of monocytes and macrophages. In: In vitro methods in cell-mediated and tumor immunity (Bloom BR, David IR, eds), pp 359-362. New York: Academic.

Kreutzberg GW, Barron KD (1978) 5'-Nucleotidase of microglial cells in the facial nucleus during axonal reaction. J Neurocytol 7:601-610.

Ling EA (1981) The origin and nature of microglia. In: Advances in cellular neurobiology (Fedoroff S, Hertz L, eds), pp 33-82. New York: Academic.

Ling EA, Wong WC (1993) The origin and nature of ramified and amoeboid microglia: a historical review and current concepts. Glia 7:9-18.

Ling EA, Kaur C, Wong WC (1982) Light and electron microscopic demonstration of non-specific esterase in amoeboid microglial cells in the corpus callosum in postnatal rats: a cytochemical link to monocytes. J Anat 135:385-394.

McGeer PL Itagaki S, Tago H, McGeer EG (1987) Reactive microglia in patients with senile dementia of the Alzheimer type are positive for the histocompatibility glycoprotein HLA-DR. Neurosci Lett 79: 195-200.

Medawar PB (1948) Immunity to homologous grafted skin. III. The fate of skin homografts transplanted to the brain, to subcutaneous tissue, and to the anterior chamber of the eye. Br J Exp Pathol 29: $58-69$.

Oehmichen M (1983) Inflammatory cells in the central nervous system. A integrating concept based on recent research in pathology, immunology, and forensic medicine. Prog Neuropathol 5:277-335.

Perry VH, Hume DA, Gordon S (1985) Immunohistochemical localization of macrophages and microglia in the adult and developing mouse brain. Neuroscience 15:313-326.

Perry VH, Matyszak MK, Fearn S (1993) Altered antigen expression of microglia in the aged rodent CNS. Glia 7:60-67.

Pulliam L, Herndier BG, Tang NM, McGrath MS (1991) Human immunodeficiency virus-infected macrophages produce soluble factors that cause histological and neurochemical alterations in cultured human brains. J Clin Invest 87:503-512.

Rio-Hortega P del (1932) Microglia. In: Cytology and cellular pathology of the nervous system (Penfield W, ed), pp 481-584. New York: Hoeber.

Rio-Hortega P del, Penfield W (1927) Cerebral cicatrix: the reaction of neuroglia and microglia to brain wounds. Johns Hopkins Hosp Bull 41:278-303.

Sievers J, Parwaresch R, Wottge U (1994) Blood monocytes and spleen macrophages differentiate into microglia-like cells on monolayers of astrocytes: morphology. Glia 12:245-258.

Stewart CC (1981) Murine mononuclear phagocytes from bone marrow. In: Methods for studying mononuclear phagocytes (Adams DO, Edelson PJ, Koren HS, eds), pp 5-20. New York: Academic.

Thanos S, Mey J, Wild M (1993) Treatment of the adult retina with microglia-suppressing factors retards axotomy-induced neuronal degradation and enhances axonal regeneration in vivo and in vitro. $\mathbf{J}$ Neurosci 13:455-466.

Ulvestad E, Williams K, Mork S, Antel J, Nyland H (1994) Phenotypic differences between human monocytes/macrophages and microglial cells studied in situ and in vitro. J Neuropathol Exp Neurol 53:492501.

Wood GW, Gollahon KA, Tilzer SA, Vats T, Morantz RA (1979) The failure of microglia in normal brain to exhibit mononuclear phagocyte markers. J Neuropathol Exp Neurol 38:369-376. 